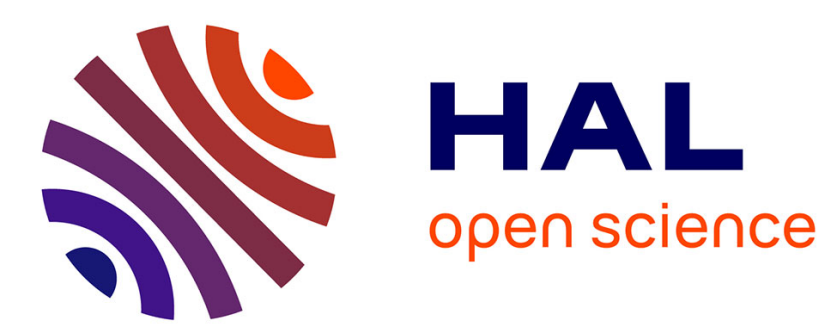

\title{
Influence of alternative donor type on early survival after hematopoietic stem cell transplantation for acute myeloid leukemia lacking a sibling donor
}

Clémence Deteix-Santana

\section{- To cite this version:}

Clémence Deteix-Santana. Influence of alternative donor type on early survival after hematopoietic stem cell transplantation for acute myeloid leukemia lacking a sibling donor. Human health and pathology. 2019. dumas-02420674

\section{HAL Id: dumas-02420674 https://dumas.ccsd.cnrs.fr/dumas-02420674}

Submitted on 20 Dec 2019

HAL is a multi-disciplinary open access archive for the deposit and dissemination of scientific research documents, whether they are published or not. The documents may come from teaching and research institutions in France or abroad, or from public or private research centers.
L'archive ouverte pluridisciplinaire HAL, est destinée au dépôt et à la diffusion de documents scientifiques de niveau recherche, publiés ou non, émanant des établissements d'enseignement et de recherche français ou étrangers, des laboratoires publics ou privés. 


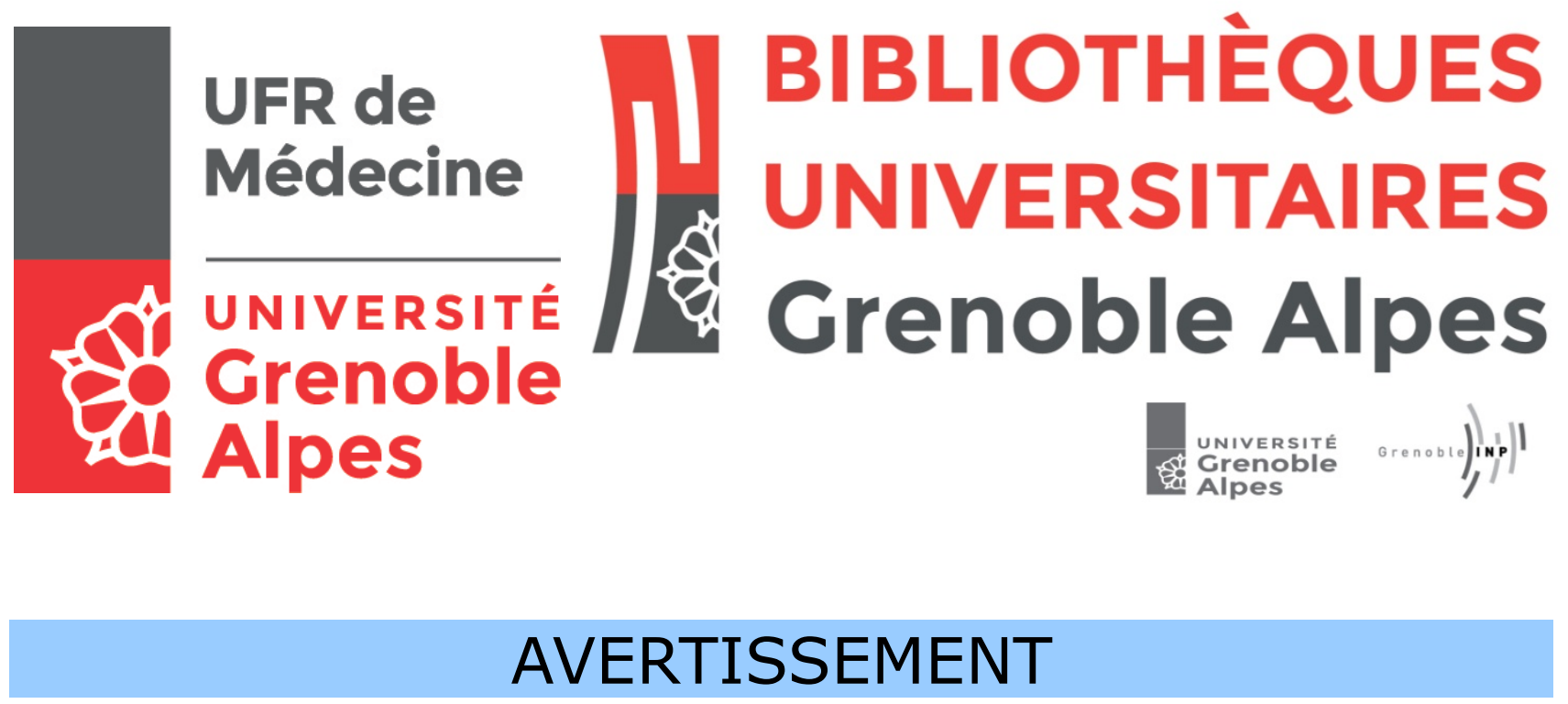

Ce document est le fruit d'un long travail approuvé par le jury de soutenance et mis à disposition de l'ensemble de la communauté universitaire élargie.

Il n'a pas été réévalué depuis la date de soutenance.

Il est soumis à la propriété intellectuelle de l'auteur. Ceci implique une obligation de citation et de référencement lors de I'utilisation de ce document.

D'autre part, toute contrefaçon, plagiat, reproduction illicite encourt une poursuite pénale.

Contact au SID de Grenoble : bump-theses@univ-grenoble-alpes.fr

\section{LIENS}

Code de la Propriété Intellectuelle. articles L 122. 4

Code de la Propriété Intellectuelle. articles L 335.2- L 335.10

http://www.cfcopies.com/juridique/droit-auteur http://www.culture.gouv.fr/culture/infos-pratiques/droits/protection.htm 
FACULTÉ DE MÉDECINE DE GRENOBLE

Année: 2019

\section{ANALYSE DE LA SURVIE DES PATIENTS ALLOGREFFÉS POUR HÉMOPATHIE MALIGNE EN L'ABSENCE DE DONNEUR GÉNOIDENTIQUE}

\section{THÈSE PRÉSENTÉE POUR L'OBTENTION DU TITRE DE DOCTEUR EN MÉDECINE}

\section{DIPLÔME D'ÉTAT}

Clémence DETEIX-SANTANA

[Données à caractère personnel]

\section{THÈSE SOUTENUE PUBLIQUEMENT LE 01/04/2019 \\ À LA FACULTÉ DE MÉDECINE DE GRENOBLE DEVANT LE JURY COMPOSÉ DE :}

M. Jean-Yves CAHN, Professeur, président du Jury

M. Frédéric GARBAN, Professeur, directeur de thèse

M. Dominique PLANTAZ, Professeur

Mme Anne THIEBAUT, Docteur 
FACULTÉ DE MÉDECINE DE GRENOBLE

Année: 2019

\section{ANALYSE DE LA SURVIE DES PATIENTS ALLOGREFFÉS POUR HÉMOPATHIE MALIGNE EN L'ABSENCE DE DONNEUR GÉNOIDENTIQUE}

\section{THÈSE PRÉSENTÉE POUR L'OBTENTION DU TITRE DE DOCTEUR EN MÉDECINE}

\section{DIPLÔME D'ÉTAT}

Clémence DETEIX-SANTANA

Née le 06/02/1989, à Clermont-Ferrand (63)

THÈSE SOUTENUE PUBLIQUEMENT LE 01/04/2019

À LA FACULTÉ DE MÉDECINE DE GRENOBLE DEVANT LE JURY COMPOSÉ DE :

M. Jean-Yves CAHN, Professeur, président du Jury

M. Frédéric GARBAN, Professeur, directeur de thèse

M. Dominique PLANTAZ, Professeur

Mme Anne THIEBAUT, Docteur 


\section{TABLE DES MATIÈRES}

ENSEIGNANTS DE L'UFR DE MÉDECINE

REMERCIEMENTS

ABRÉVIATIONS

INTRODUCTION

ARTICLE

Résumé

Abstract

Introduction

Patients et méthodes

Résultats

Discussion

Conclusion

CONCLUSION p35

BIBLIOGRAPHIE p36

TABLES ET FIGURES p38 


\title{
LISTE DES ENSEIGNANTS DE L'UFR DE MEDECINE
}

\author{
Doyen de la Faculté : Pr. Patrice MORAND
}

Année 2018-2019

ENSEIGNANTS DE L'UFR DE MEDECINE

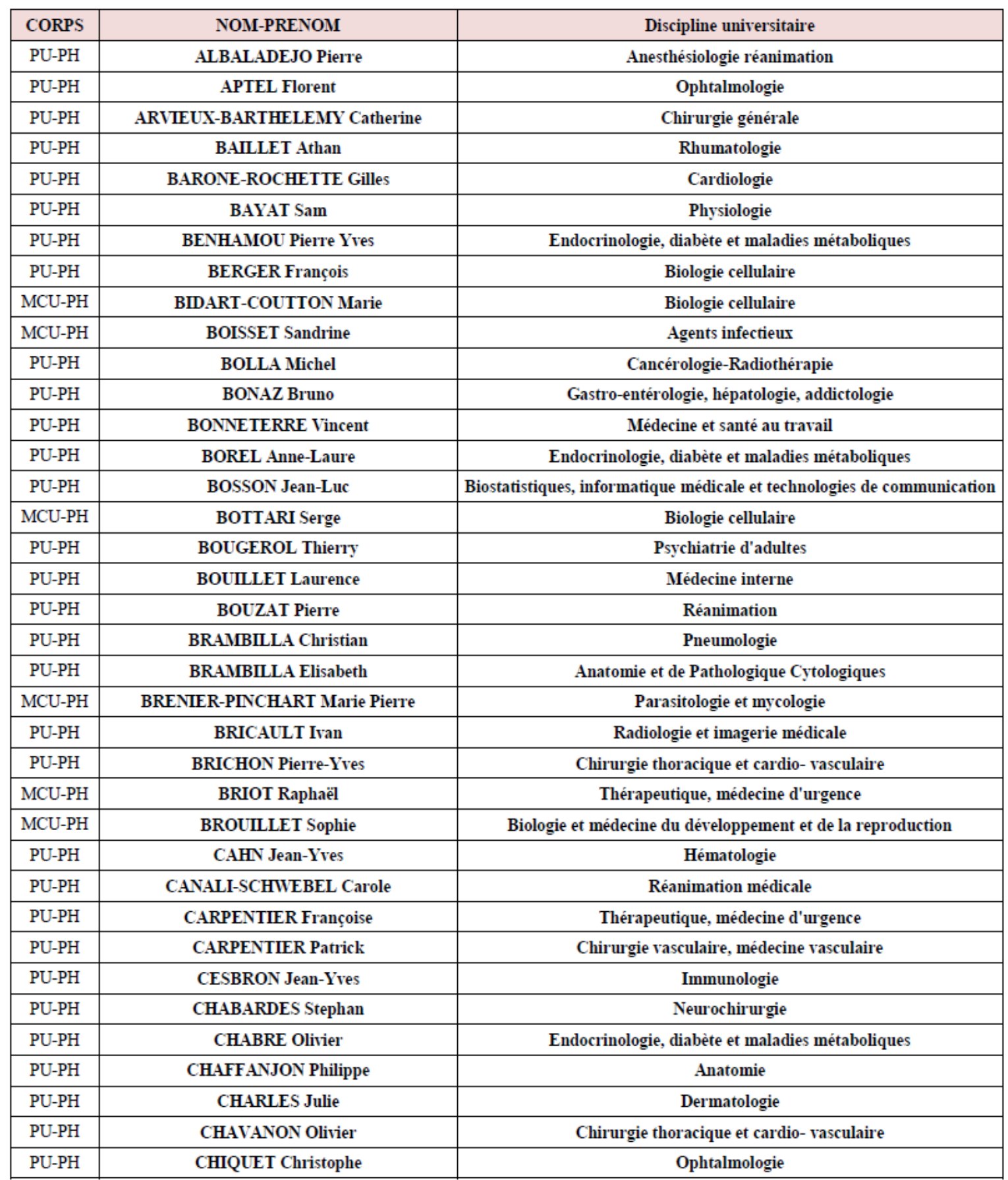




\begin{tabular}{|c|c|c|}
\hline CORPS & NOM-PRENOM & Discipline universitaire \\
\hline PU-PH & CHIRICA Mircea & Chirurgie générale \\
\hline PU-PH & CINQUIN Philippe & Biostatistiques, informatique médicale et technologies de communication \\
\hline MCU-PH & CLAVARINO Giovanna & Immunologie \\
\hline PU-PH & COHEN Olivier & Biostatistiques, informatique médicale et technologies de communication \\
\hline PU-PH & COURVOISIER Aurélien & Chirurgie infantile \\
\hline PU-PH & COUTTON Charles & Génétique \\
\hline PU-PH & COUTURIER Pascal & Gériatrie et biologie du vieillissement \\
\hline PU-PH & CRACOWSKI Jean-Luc & Pharmacologie fondamentale, pharmacologie clinique \\
\hline PU-PH & CURE Hervé & Oncologie \\
\hline PU-PH & DEBATY Guillaume & Médecine d'Urgence \\
\hline PU-PH & DEBILLON Thierry & Pédiatrie \\
\hline PU-PH & DECAENS Thomas & Gastro-entérologie, Hépatologie \\
\hline PU-PH & DEMATTEIS Maurice & Addictologie \\
\hline PU-PH & DEMONGEOT Jacques & Biostatiques, informatique médicale et technologies de communication \\
\hline MCU-PH & DERANSART Colin & Physiologie \\
\hline PU-PH & DESCOTES Jean-Luc & Urologie \\
\hline PU-PH & DETANTE Olivier & Neurologie \\
\hline MCU-PH & DIETERICH Klaus & Génétique et procréation \\
\hline MCU-PH & DOUTRELEAU Stéphane & Physiologie \\
\hline MCU-PH & DUMESTRE-PERARD Chantal & Immunologie \\
\hline PU-PH & EPAULARD Olivier & Maladies Infectieuses et Tropicales \\
\hline PU-PH & ESTEVE François & Biophysique et médecine nucléaire \\
\hline MCU-PH & EYSSERIC Hélène & Médecine légale et droit de la santé \\
\hline PU-PH & FAGRET Daniel & Biophysique et médecine nucléaire \\
\hline PU-PH & FAUCHERON Jean-Luc & Chirurgie générale \\
\hline MCU-PH & FAURE Julien & Biochimie et biologie moléculaire \\
\hline PU-PH & FERRETTI Gilbert & Radiologie et imagerie médicale \\
\hline PU-PH & FEUERSTEIN Claude & Physiologie \\
\hline PU-PH & FONTAINE Éric & Nutrition \\
\hline PU-PH & FRANCOIS Patrice & Epidémiologie, économie de la santé et prévention \\
\hline MCU-MG & GABOREAU Yoann & Médecine Générale \\
\hline PU-PH & GARBAN Frédéric & Hématologie, transfusion \\
\hline PU-PH & GAUDIN Philippe & Rhumatologie \\
\hline PU-PH & GAVAZZI Gaétan & Gériatrie et biologie du vieillissement \\
\hline PU-PH & GAY Emmanuel & Neurochirurgie \\
\hline MCU-PH & GILLOIS Pierre & Biostatistiques, informatique médicale et technologies de communication \\
\hline PU-PH & GIOT Jean-Philippe & Chirurgie plastique, reconstructrice et esthétique \\
\hline MCU-PH & GRAND Sylvie & Radiologie et imagerie médicale \\
\hline PU-PH & GRIFFET Jacques & Chirurgie infantile \\
\hline MCU-PH & GUZUN Rita & Endocrinologie, diabétologie, nutrition, éducation thérapeutique \\
\hline PU-PH & HAINAUT Pierre & Biochimie, biologie moléculaire \\
\hline PU-PH & HALIMI Serge & Nutrition \\
\hline PU-PH & HENNEBICQ Sylviane & Génétique et procréation \\
\hline PU-PH & HOFFMANN Pascale & Gynécologie obstétrique \\
\hline PU-PH & HOMMEL Marc & Neurologie \\
\hline PU-MG & IMBERT Patrick & Médecine Générale \\
\hline PU-PH & JOUK Pierre-Simon & Génétique \\
\hline
\end{tabular}




\begin{tabular}{|c|c|c|}
\hline CORPS & NOM-PRENOM & Discipline universitaire \\
\hline PU-PH & JUVIN Robert & Rhumatologie \\
\hline PU-PH & KAHANE Philippe & Physiologie \\
\hline MCU-PH & KASTLER Adrian & Radiologie et imagerie médicale \\
\hline PU-PH & KRAINIK Alexandre & Radiologie et imagerie médicale \\
\hline PU-PH & LABARERE José & Epidémiologie ; Eco. de la Santé \\
\hline MCU-PH & LABLANCHE Sandrine & Endocrinologie, diabète et maladies métaboliques \\
\hline MCU-PH & LANDELLE Caroline & Bactériologie - virologie \\
\hline MCU-PH & LARDY Bernard & Biochimie et biologie moléculaire \\
\hline $\mathrm{MCU}-\mathrm{PH}$ & LE PISSART Audrey & Biochimie et biologie moléculaire \\
\hline PU-PH & LECCIA Marie-Thérèse & Dermato-vénéréologie \\
\hline PU-PH & LEROUX Dominique & Génétique \\
\hline PU-PH & LEROY Vincent & Gastro-entérologie, hépatologie, addictologie \\
\hline PU-PH & LETOUBLON Christian & Chirurgie digestive et viscérale \\
\hline PU-PH & LEVY Patrick & Physiologie \\
\hline PU-PH & LONG Jean-Alexandre & Urologie \\
\hline MCU-PH & LUPO Julien & Virologie \\
\hline PU-PH & MAGNE Jean-Luc & Chirurgie vasculaire \\
\hline MCU-PH & MAIGNAN Maxime & Médecine d'urgence \\
\hline PU-PH & MAITRE Anne & Médecine et santé au travail \\
\hline MCU-PH & MALLARET Marie-Reine & Epidémiologie, économie de la santé et prévention \\
\hline PU-PH & MALLION Jean-Michel & Cardiologie \\
\hline MCU-PH & MARLU Raphaël & Hématologie, transfusion \\
\hline MCU-PH & MAUBON Danièle & Parasitologie et mycologie \\
\hline PU-PH & MAURIN Max & Bactériologie - virologie \\
\hline MCU-PH & MC LEER Anne & Cytologie et histologie \\
\hline PU-PH & MORAND Patrice & Bactériologie - virologie \\
\hline PU-PH & MOREAU-GAUDRY Alexandre & Biostatistiques, informatique médicale et technologies de communication \\
\hline PU-PH & MORO Elena & Neurologie \\
\hline PU-PH & MORO-SIBILOT Denis & Pneumologie \\
\hline PU-PH & MOUSSEAU Mireille & Cancérologie \\
\hline PU-PH & MOUTET François & Chirurgie plastique, reconstructrice et esthétique ; brûlologie \\
\hline MCU-PH & PACLET Marie-Hélène & Biochimie et biologie moléculaire \\
\hline PU-PH & PALOMBI Olivier & Anatomie \\
\hline PU-PH & PARK Sophie & Hémato - transfusion \\
\hline PU-PH & PASSAGGIA Jean-Guy & Anatomie \\
\hline PU-PH & PAYEN DE LA GARANDERIE Jean-François & Anesthésiologie réanimation \\
\hline MCU-PH & PAYSANT François & Médecine légale et droit de la santé \\
\hline MCU-PH & PELLETIER Laurent & Biologie cellulaire \\
\hline PU-PH & PELLOUX Hervé & Parasitologie et mycologie \\
\hline PU-PH & PEPIN Jean-Louis & Physiologie \\
\hline PU-PH & PERENNOU Dominique & Médecine physique et de réadaptation \\
\hline PU-PH & PERNOD Gilles & Médecine vasculaire \\
\hline PU-PH & PIOLAT Christian & Chirurgie infantile \\
\hline PU-PH & PISON Christophe & Pneumologie \\
\hline PU-PH & PLANTAZ Dominique & Pédiatrie \\
\hline PU-PH & POIGNARD Pascal & Virologie \\
\hline PU-PH & POLACK Benoît & Hématologie \\
\hline
\end{tabular}




\begin{tabular}{|c|c|c|}
\hline CORPS & NOM-PRENOM & Discipline universitaire \\
\hline PU-PH & POLOSAN Mircea & Psychiatrie d'adultes \\
\hline PU-PH & PONS Jean-Claude & Gynécologie obstétrique \\
\hline PU-PH & RAMBEAUD Jean-Jacques & Urologie \\
\hline PU-PH & RAY Pierre & Biologie et médecine du développement et de la reproduction \\
\hline MCU-PH & RENDU John & Biochimie et Biologie Moléculaire \\
\hline MCU-PH & RIALLE Vincent & Biostatiques, informatique médicale et technologies de communication \\
\hline PU-PH & RIGHINI Christian & Oto-rhino-laryngologie \\
\hline PU-PH & ROMANET Jean Paul & Ophtalmologie \\
\hline PU-PH & ROSTAING Lionel & Néphrologie \\
\hline MCU-PH & ROUSTIT Matthieu & Pharmacologie fondamentale, pharmaco clinique, addictologie \\
\hline MCU-PH & ROUX-BUISSON Nathalie & Biochimie, toxicologie et pharmacologie \\
\hline MCU-PH & RUBIO Amandine & Pédiatrie \\
\hline PU-PH & SARAGAGLIA Dominique & Chirurgie orthopédique et traumatologie \\
\hline MCU-PH & SATRE Véronique & Génétique \\
\hline PU-PH & SAUDOU Frédéric & Biologie Cellulaire \\
\hline PU-PH & SCHMERBER Sébastien & Oto-rhino-laryngologie \\
\hline PU-PH & SCOLAN Virginie & Médecine légale et droit de la santé \\
\hline MCU-PH & SEIGNEURIN Arnaud & Epidémiologie, économie de la santé et prévention \\
\hline PU-PH & STAHL Jean-Paul & Maladies infectieuses, maladies tropicales \\
\hline PU-PH & STANKE Françoise & Pharmacologie fondamentale \\
\hline MCU-PH & STASIA Marie-José & Biochimie et biologie moléculaire \\
\hline PU-PH & STURM Nathalie & Anatomie et cytologie pathologiques \\
\hline PU-PH & TAMISIER Renaud & Physiologie \\
\hline PU-PH & TERZI Nicolas & Réanimation \\
\hline MCU-PH & TOFFART Anne-Claire & Pneumologie \\
\hline PU-PH & TONETTI Jérôme & Chirurgie orthopédique et traumatologie \\
\hline PU-PH & TOUSSAINT Bertrand & Biochimie et biologie moléculaire \\
\hline PU-PH & VANZETTO Gérald & Cardiologie \\
\hline PU-PH & VUILLEZ Jean-Philippe & Biophysique et médecine nucléaire \\
\hline PU-PH & WEIL Georges & Epidémiologie, économie de la santé et prévention \\
\hline PU-PH & ZAOUI Philippe & Néphrologie \\
\hline PU-PH & ZARSKI Jean-Pierre & Gastro-entérologie, hépatologie, addictologie \\
\hline
\end{tabular}

PU-PH : Professeur des Universités et Praticiens Hospitaliers

MCU-PH : Maitre de Conférences des Universités et Praticiens Hospitaliers

PU-MG : Professeur des Universités de Médecine Générale

MCU-MG : Maître de Conférences des Universités de Médecine Générale 


\section{REMERCIEMENTS}

\section{A mon jury de thèse,}

Jean-Yves Cahn, pour votre accompagnement tout au long de mon internat et pour vos coups de pouce indispensables dans les choix d'inter-CHU et d'assistanat. L'hématologie grenobloise va me manquer, mais Lyon n'est pas si loin et j'espère bien garder contact.

Frédéric Garban, pour avoir initié ce sujet de thèse qui m'a vraiment passionné même si on est toujours déçu de ne pas apporter de conclusions encore plus pertinentes et novatrices.

Anne, pour ta patience et tes enseignements lors de mon premier semestre il y a déjà 5 ans et demi. Jeune interne facilement paniquée, j'ai apprécié ta constance et ton calme qui s'appuient sur des compétences solides et une grande expérience dans la greffe.

Dominique Plantaz, pour votre accueil en onco-hématologie pédiatrique, probablement un de mes meilleurs stages tant sur le plan des apprentissages que sur le plan humain. J'ai peut-être raté une vocation!

A vous, chers hématologues, dans l'ordre où nous avons fait plus ample connaissance,

Claude-Eric, pour ton dynamisme permanent et nos courses à la contre-visite quand tu réussissais à voir 10 patients alors que je n'en voyais que 4... Merci aussi pour Actu-greffe ! Brigitte, tu m'as appris à approfondir les dossiers et à ne rien laisser de côté. Mon côté parfois expéditif en a pris un coup! Merci pour ces 6 mois en hôpital de jour et pour ton témoignage lors de ton départ en retraite. La barre est haute !

Philippe, pour tes enseignements passionnés sur la transfusion, cette partie de l'hématologie que nous connaissons si peu finalement et pour ton ouverture sur d'autres horizons où j'ai beaucoup à apprendre. Merci pour ta disponibilité lors de mon passage chez vous.

Caroline, pour ton encadrement et ton enseignement sur la drépanocytose. Il m'a été très utile lors de mon inter-CHU parisien.

Sophie, pour votre approche de la myélodysplasie qui me l'a rendue plus sympathique et pour le projet sur l'IDO lors de mon semestre de biologie.

Les médecins du $5^{\text {ème }}$ B pour m'avoir soutenue, malgré vous, lors de mes 2 « couvées »... Lysiane, pour la transmission de tes nombreuses connaissances, tes réponses efficaces à 
chacune de mes questions et ta lucidité sur de nombreux sujets hors hémato. Merci pour toutes les chaises que tu m'as apportées ! Le surnom de Maman du B te va si bien!

Rémy, si je pouvais, je le chanterais... Merci pour vos enseignements si calés, votre entrain dès le matin et votre souci du patient. Toujours partant, vous savez transmettre votre passion pour le lymphome. Et non, je n'aurais pas accouché dans le service !

Stéphane, pour ta franchise, ta bienveillance à mon égard et ta compagnie certains aprèsmidis dans notre bureau. Tu as toujours un sujet de conversation exotique.

Martin, pour ta motivation sans faille, ton accueil et tes conseils lorsque je suis arrivée à l'internat, ton « squattage » de labo à Istanbul qui nous a permis de passer de bonnes soirées et tes encouragements pour cette thèse.

Clara, pour tous tes conseils toujours si avisés quelque soit le thème: organisation, myélome, vacances à vélo, enfants...

Sylvain, pour ta constance et ta rigueur. Pour les petites discussions lors des transmissions.

Caro, ma première co-interne, pour ta patience il y a 5 ans, ton dynamisme, ta folie, tous les potins du CHU, ta fidélité à toi-même, tes magnifiques poses de voie centrale, ton lien avec les patients et ton écoute.

Vous, les médecins d'Annecy, Frédérique, Nicolas, Anne, Claire et Stéphanie, j'aurais vraiment aimé revenir travailler à vos côtés. Peut-être un jour, qui sait ? C'était un régal !

\section{A vous, chers co-internes,}

Mathilde et Mathieu, spéciale dédicace pour ces 5 mois. Merci d'avoir doublé mes neurones de femme enceinte, merci pour votre flexibilité quant à certains après-midi fantômes (avec Paul ou avec 1'«Anglaise »), merci pour les beaux spectacles auxquels j'ai pu assister en dictant mes courriers et pour les nombreux thés et matés partagés.

Natacha, Christina, Claire, Paul, Lucile, Eléonore, Fabien et Lauren pour toutes ces années d'internat partagées. C'était un plaisir d'avancer avec vous.

Charlotte, Josquin, Cédric et Laure, qui avez tant essayé de me convaincre d'un remord en médecine générale! Mais non, « Hématome » a continué dans sa voie.

Audrey, Yann et Loïc, vous allez faire de très bons médecins. 
Claire, Aldric, Martin, Virgile, Mathilde, Anne, Véronique et Aude pour nos aventures en réanimation. Un semestre mémorable !

A vous, chères infirmières, pour votre patience avec nous et vos remises en question de nos prescriptions. Nos métiers se complètent bien.

A vous, chers ARCs, vous m'avez plus d'une fois sauvé la mise. Merci pour votre disponibilité à toute épreuve. Merci Barbara pour les quelques goûters improvisés.

A vous, chers patients, c'est sans nul doute vous qui m'avez le plus appris.

\section{A ma famille,}

Andrés, tu es tout simplement trop fort.

Paul, pour ta joie de vivre et ton énergie inépuisable.

$« ? »$, pour me rappeler qu'il faut parfois ralentir le rythme.

Papa et Maman, pour m'avoir soutenue et poussée dans cette vocation médicale, pour votre exemple de travailleurs organisés et parce que vous ne reculez devant rien. J'en profite pour saluer votre santé de fer.

Mes frères et sœurs, mes beaux-frères et belles-sœurs, Christophe, Marie-Astrid, AnneSophie, Geoffroy, Caroline, François, Guillaume et Isabelle, parce que vous êtes de grands exemples pour la "p'tite» que je suis. A chaque étape, vous êtes là et ça me touche énormément.

Mes neveux et nièces, pour tous les supers moments que nous passons ensemble. C'est toujours un délice.

Ma belle-famille, pour tous les nouveaux horizons que vous me faites découvrir.

A Claire, pour ton amitié fidèle, ton écoute quelle que soit l'heure du jour ou de la nuit, ton témoignage de vie et ton sourire dans la difficulté.

A Marie, Inès, Marie la charmille et Steph pour ces années folles d'externat. 


\section{ABRÉVIATIONS ANGLAISES}

AML: Acute Myeloid Leukemia

CMV: CytoMegaloVirus

CR: Complete Remission

EBMT : European Society for Blood and Marrow Transplant

GVHD: Graft Versus Host Disease

GVL: Graft Versus Leukemia

HCT: Hematopoietic stem Cell Transplant

HLA: Human Leukocyte Antigen

HR: Hazard Ratio

HSC: Hematopoietic Stem Cell

MAC: MyeloAblative Conditioning

mMUD: misMatch Unrelated Donor

MRD: Match Related Donor

MUD: Match Unrelated Donor

OS: Overall Survival

OSAR: Overall Survival After Registration

OSAT: Overall Survival After Transplant

RIC: Reduced Intensity Conditioning

TRM: Treatment-Related Mortality

UCB: Umbilical Cord Blood 


\section{ABRÉVIATIONS FRANÇAISES}

ABM : Agence de la BioMédecine

ACSH : Allogreffe de Cellules Souches Hématopoïétiques

CSH : Cellules Souches Hématopoïétiques

GVL : Greffon Versus Leucémie

CMV : CytoMegaloVirus

LAM : Leucémie Aiguë Myéloïde

SFGM-TC : Société Francophone de Greffe de Moelle et de Thérapie Cellulaire

USP : Unité de Sang Placentaire 


\section{INTRODUCTION}

L’Allogreffe de Cellules Souches Hématopoïétiques (ACSH) est une immunothérapie cellulaire dont le champ d'application est principalement les hémopathies malignes. Son action anti-tumorale résulte à la fois de la chimiothérapie intensive administrée avant la greffe et de l'effet GVL (Greffon Versus Leucémie) dû aux cellules immunocompétentes du greffon. L'ACSH a connu de profondes évolutions, conduisant à une augmentation continue du nombre de greffes réalisées annuellement. Parmi ces évolutions, on retrouve la diversification des sources de Cellules Souches Hématopoïétiques (CSH) : moelle osseuse ou cellules souches périphériques, l'apparition de conditionnements d'intensité réduite compatibles avec la réalisation de greffe chez des patients plus âgés ou plus fragiles ou encore le développement d'autres types de donneurs avec l'arrivée des donneurs alternatifs. L'ACSH n'en reste pas moins associée à une morbidité et une mortalité importantes liées notamment à la maladie du greffon contre l'hôte et aux complications infectieuses. De plus, à l'heure des maîtrises des dépenses de santé, le poids économique de cette procédure doit être un élément de réflexion.

\section{JUSTIFICATION DE L'ETUDE}

L'ACSH est considérée comme le seul traitement potentiellement curatif pour certaines hémopathies malignes et en particulier la leucémie aiguë. Trouver un donneur est une étape importante du programme thérapeutique. Lorsque le diagnostic est posé avec une indication d'allogreffe, le typage des antigènes leucocytaires humains (HLA, Human Leukocyte Antigen) des frères et sœurs du patient est recherché. Les donneurs apparentés HLA-compatibles sont considérés comme les meilleurs donneurs (gold standard) mais seulement $30 \%$ des patients ont ce type de donneur une fois les facteurs tels que l'état de 
santé du donneur et le consentement pris en compte. ${ }^{1}$ En l'absence de donneur compatible dans la fratrie, le patient est inscrit sur les registres nationaux et internationaux à la recherche d'un donneur non apparenté. La compatibilité entre donneur et receveur pour les molécules HLA de classe I (A, B et C) et de classe II (DRB1, DQB1) est capitale dans le bon déroulement d'une ACSH. En Europe, le standard est de rechercher un donneur HLAcompatible pour ces 5 molécules (donneur 10/10) alors que dans d'autres pays dont les Etats-Unis, la compatibilité pour le DQB1 n'est pas requise et seules les 4 premières molécules sont étudiées (donneur 8/8). La probabilité de trouver un tel donneur HLA 10/10 ou $8 / 8$ est fortement influencée par l'origine du patient et varie entre $75 \%$ pour les caucasiens et moins de $20 \%$ pour certains groupes ethniques comme les afro-américains. ${ }^{2}$

Depuis ces dernières années, des sources alternatives de donneur ont été adoptées avec une indication validée en l'absence de donneur HLA-compatible : non apparenté HLA 9/10, Unité de Sang Placentaire (USP) ou apparenté haploidentique (haplo).

Dans le contexte des Leucémies Aiguë Myéloïdes (LAM), plusieurs études se sont intéressées au devenir des patients allogreffés avec un donneur apparenté HLAcompatible ou un donneur non apparenté HLA 10/10. Dans la première étude, la toxicité liée à la procédure (mortalité toxique) est augmentée en cas de donneur non apparenté alors que le taux de rechute, la survie sans leucémie et la survie globale sont identiques. ${ }^{3}$ Ces données de survie globale et de survie sans leucémie ont été confirmées par Saber et al. ${ }^{4}$, dans la même indication des LAM. Une étude prospective multicentrique menée entre 1998 et 2004 par Schlenk et al. a également montré la similarité des résultats après ACSH que le donneur soit apparenté ou non. ${ }^{5}$ Enfin, en ce qui concerne les résultats post-greffe à long terme, dans une étude prospective internationale multicentrique, Hows et al n'ont pas retrouvé de différence significative en terme de survie à 12 ans entre les apparentés HLAcompatibles $(77 \%+/-5 \%)$ et les non apparentés HLA 10/10 (67\% +/- 11\%). Il n'y avait pas 
de différence sur le taux de décès tardifs : respectivement, $21 \%$ et $30 \%$. Seule l'incidence cumulative de maladie du greffon contre l'hôte chronique était plus importante chez les receveurs non apparentés HLA 10/10. ${ }^{6}$

Sans donneur HLA-compatible (apparenté ou non), la meilleure alternative entre les autres types de donneurs (non apparentés HLA 9/10, USP ou haplo) n'est pas connue.

Les donneurs non apparentés avec une compatibilité réduite $(9 / 10)$ ont représenté la première alternative historique. Comparées aux greffes de donneurs HLA-compatibles, les greffes de donneurs HLA 9/10 ont une perte de 10\% de survie globale en raison d'une augmentation de la mortalité toxique. ${ }^{7}$ L'étude de Lee et al. ${ }^{8}$ a montré l'impact négatif de la présence d'un mismatch (HLA-A, -B, -C, ou -DRB1, de faible ou de haute résolution) en termes de survie globale à 1 an (43\% versus $52 \%$ en $8 / 8)$, de survie sans maladie, de mortalité toxique et d'augmentation du risque de maladie du greffon contre l'hôte aiguë, après des greffes de moelle osseuse avec un conditionnement standard (myéloablatif). Les effets d'une incompatibilité allélique ou antigénique ne diffèrent pas sur le plan statistique. Les incompatibilités HLA-B ou -C sont mieux tolérées que celles concernant les loci HLA-A et -DRB1. Les incompatibilités HLA-DP ou -DQ ne sont pas associées à une modification de la survie.

Les unités de sang placentaires provenant de dons de cordons ombilicaux sont utilisés comme source de cellules souches depuis les années 1980 avec plusieurs avantages: disponibilité rapide, critères de sélection HLA moins restrictifs, absence de risque pour le donneur, risque relativement faible de maladie du greffon contre l'hôte et représentativité ethnique plus large. Toutefois, leurs indications restent limitées du fait d'une quantité de cellules souches plus faible, d'un délai de prise de greffe plus long qui engendre une 
augmentation du risque de complications infectieuses, de l'absence de possibilité de thérapies cellulaires post-greffe (injection de lymphocytes du donneur) et de leur coût. ${ }^{9}$ Plusieurs études ont montré des résultats similaires en terme de survie à long-terme posttransplantation entre les USP ou les donneurs non apparentés HLA 10/10 dans des conditions variées: greffe d'une ou deux unités de sang de cordon, conditionnement myéloablatif ou d'intensité réduite, patients jeunes ou âgés. ${ }^{10,11}$ Certains auteurs ont montré une plus grande incidence de rechute après une greffe de sang placentaire pour des patients atteints de LAM de haut risque comparé aux donneurs apparentés HLA-compatibles et aux donneurs non apparentés HLA 10/10. ${ }^{10,12}$

Les greffes haploidentiques représentent une autre alternative et sont l'objet d'un engouement récent. Il s'agit de donneurs apparentés parmi les ascendants, les descendants ou les cousins du patient. Parmi les centres de l'EBMT (European Society for Blood and Marrow Transplant), la proportion de greffes haploidentiques pour des hémopathies malignes ou non est passée de $2,5 \%$ dans les années 2005 à $291 \%$ depuis $2015^{13}$. Une large série prospective multicentrique de greffes haploidentiques entre 2010 et 2013 chez des adultes atteints de LAM de risque intermédiaire ou élevé en première rémission complète a montré une survie sans leucémie de presque $70 \%$ et une incidence très basse de maladie du greffon contre l'hôte à la fois aiguë et chronique. ${ }^{14}$ Ciurea et al. ont montré une survie globale à 3 ans comparable après greffe de donneur haploidentique versus donneur non apparenté HLA 10/10 chez des patients atteints de LAM dans une étude rétrospective multicentrique menée entre 2008 et 2012, même après ajustement sur le stade de la maladie et sur le risque cytogénétique. ${ }^{15}$ Ils ont également montré un taux de maladie du greffon contre l'hôte plus bas après greffe haploidentique. Un des avantages majeurs de la greffe haploidentique est d'éviter une recherche longue et coûteuse de donneur sur le registre international. En effet, le délai de recherche du donneur peut allonger l'intervalle de temps 
entre la rémission et la greffe et augmenter ainsi le risque de progression ou de rechute de la maladie. $^{16}$

A notre connaissance, il n'y a pas d'essai prospectif randomisé comparant les résultats des greffes de donneurs alternatifs : non apparentés 9/10, USP, haplo. Une étude de phase III multicentrique randomisé est en cours pour clarifier l'efficacité de la greffe à partir d'unités doubles de sang placentaire et à partir de donneurs haploidentiques. ${ }^{17}$

Les données de l'Agence de la BioMédecine (ABM) confirment qu'il existe concrètement en France une évolution dans le choix des donneurs ces dernières années. ${ }^{18}$ Les greffes non apparentées, majoritaires depuis 2007 , sont passées de $58,2 \%$ à $52,5 \%$ des allogreffes réalisées entre 2013 et 2017 . C'est le développement des greffes haploidentiques (375 greffes en 2017 , soit $41,5 \%$ des greffes apparentées) qui explique l'augmentation progressive du nombre total des greffes apparentées.

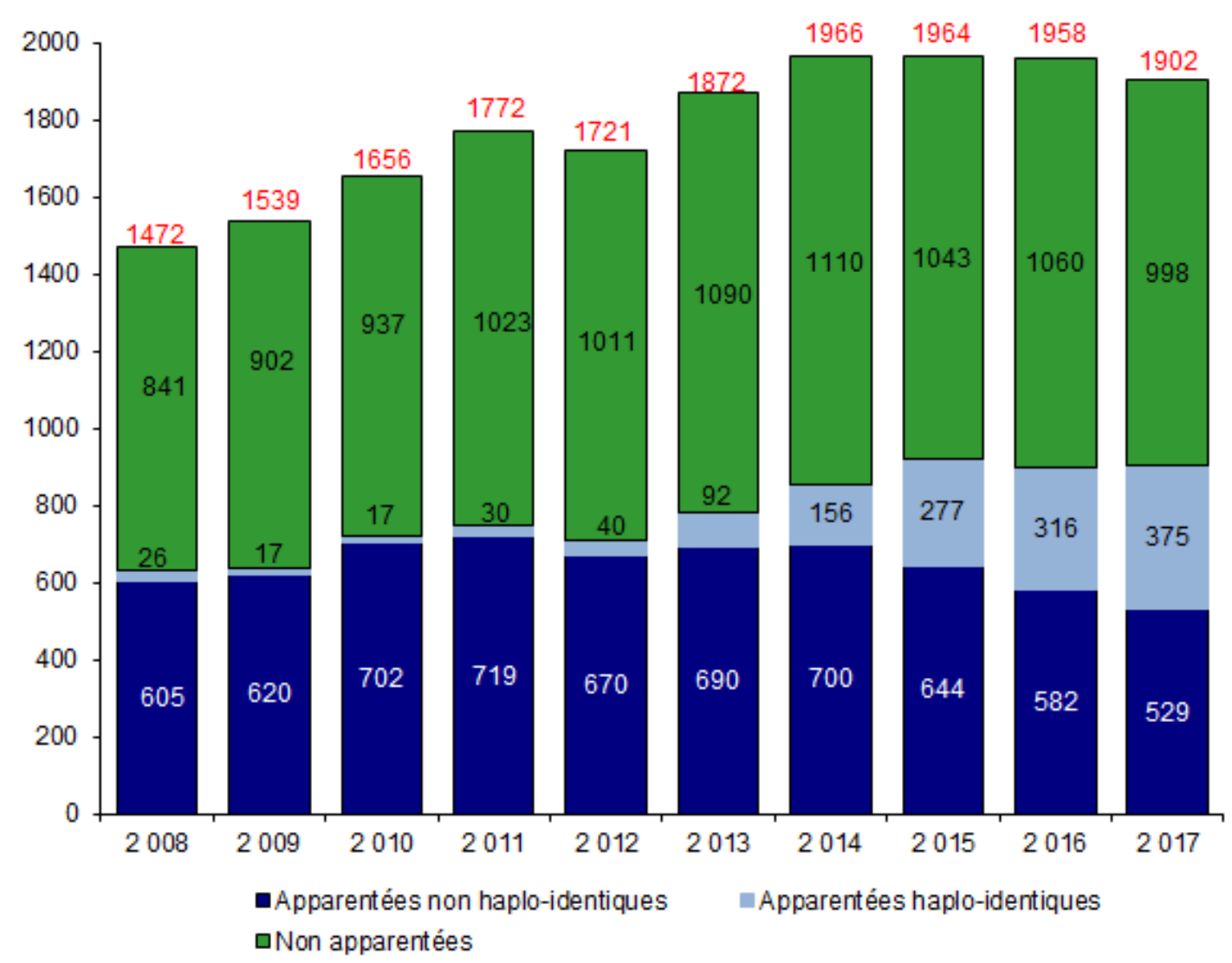

Evolution du nombre d'allogreffe de CSH selon le type de donneur ${ }^{18}$ 
La répartition des allogreffes de CSH en France sur l'année 2017 selon le type de donneur confirme à nouveau le recours important aux donneurs haploidentiques comparés aux USP.

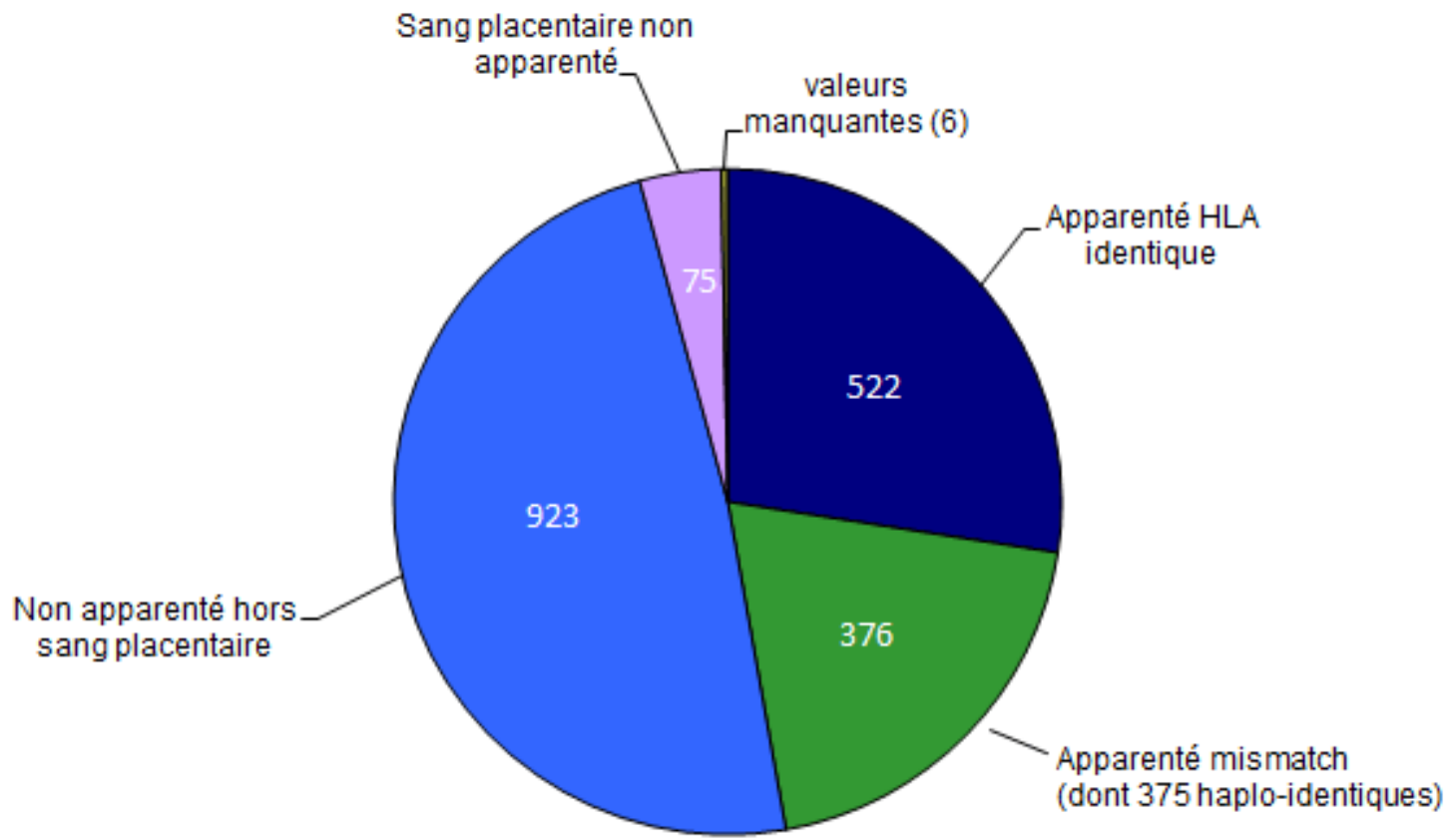

Répartition des allogreffes de CSH selon le type de donneur ${ }^{18}$

En ce qui concerne le délai entre l'inscription et la greffe, les données de l'ABM pour les ACSH en France issues de donneur non apparenté en 2017 révèlent une durée inférieure à 6 mois dans $81 \%$ des cas. Plus précisément, dans le cadre des LAM, le délai entre l'inscription et la confirmation du typage est de 36 jours, celui entre la confirmation du typage et le recrutement est de 7 jours et celui entre le recrutement et le prélèvement est de 41 jours donnant un délai médian total de 98 jours ( $\min =12$ jours ; max=1203jours). 


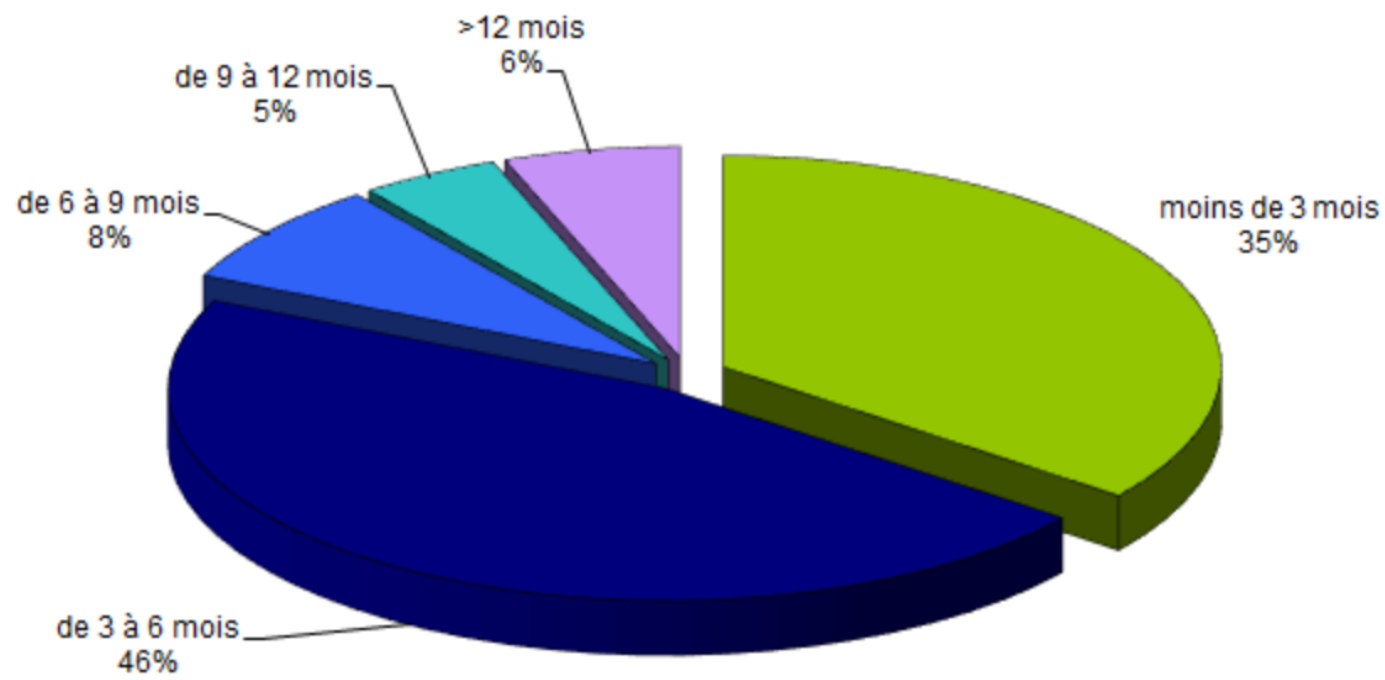

Délai entre l'inscription et la greffe des patients français ayant bénéficié d'un greffon de CSH issu de donneur non apparenté en $2017(\mathrm{~N}=926)^{18}$

\section{HYPOTHÈSE DE L'ETUDE}

Dans notre étude, nous recherchons l'influence du type de donneur sur la survie précoce post-transplantation en prenant en considération le délai de recherche du donneur et d'organisation de la procédure. C'est une manière d'étudier les complications spécifiques de chaque donneur (en dehors de la rechute) dans les 12 mois post-greffe. Plus précisément, nous avons regardé la survie globale dans les 18 mois après inscription au registre international sur un intervalle de temps court (2012-2016) dans une population homogène de patients : adultes atteints de LAM ; selon 3 groupes en fonction du donneur : non apparenté HLA 9/10, USP et haplo en comparaison avec les apparentés HLA 10/10. 


\section{ARTICLE}

\section{Influence of alternative donor type on early survival after hematopoietic stem cell transplantation for acute myeloid leukemia lacking a sibling donor}

Clémence Deteix ${ }^{1}$, Florence Mesnil ${ }^{2}$, Sabine Furst ${ }^{3}$, Noel Milpied ${ }^{4}$, Ibrahim Yakoub-Agha ${ }^{5}$, Nathalie Fegueux ${ }^{6}$, Régis Peffault de Latour ${ }^{7}$, Mohamad Mohty ${ }^{8}$, Patrice Chevallier ${ }^{9}$, Hélène Labussière Wallet $^{10}$, Anne Huynh ${ }^{11}$, Fabrice Larosa ${ }^{12}$, Jean-Henri Bourhis ${ }^{13}$, Jean-Yves Cahn $^{1}$, Sylvain Chantepie ${ }^{14}$, Jacques-Olivier Bay ${ }^{15}$, Françoise Audat ${ }^{2}$, Alison Foote ${ }^{1}$, Catherine Faucher ${ }^{2}$, Evelyne Marry ${ }^{2}$ and Frédéric Garban ${ }^{1,2}$ on behalf of the Société Francophone de Greffe de Moelle et de Thérapie Cellulaire (SFGM-TC)

${ }^{1} \mathrm{CHU}$ (University Hospital) de Grenoble Alpes, Grenoble, France,

${ }^{2}$ Agence de la Biomédecine, La Plaine Saint Denis, France,

${ }^{3}$ Institut Paoli Calmette, Marseille, France,

${ }^{4} \mathrm{CHU}$ de Bordeaux, Bordeaux, France,

${ }^{5}$ CHRU de Lille, LIRIC, INSERM U995, Université de Lille, Lille, France,

${ }^{6} \mathrm{CHU}$ de Montpellier, Montpellier, France,

${ }^{7}$ CHU Saint-Louis, Paris, France,

${ }^{8} \mathrm{CHU}$ Saint-Antoine, Paris, France

${ }^{9} \mathrm{CHU}$ de Nantes, Nantes, France

${ }^{10}$ Hospices Civils de Lyon, CH Lyon Sud, Lyon, France

${ }^{11}$ Oncopole CHU Toulouse, Toulouse, France

${ }^{12} \mathrm{CHU}$ de Besançon, Besançon, France

${ }^{13}$ Institut Gustave Roussy, Villejuif, France

${ }^{14} \mathrm{CHU}$ de Caen, Caen, France

${ }^{15} \mathrm{CHU}$ de Clermont-Ferrand, Clermont-Ferrand, France 


\section{RÉSUMÉ}

L'allogreffe de cellules souches hématopoḯtiques est le seul traitement potentiellement curateur des leucémies aiguës myéloïdes (LAM). En l'absence de donneur génoidentique ou compatible en HLA (Human Leukocyte Antigen) 10/10, une allogreffe reste possible grâce à 3 types de donneurs alternatifs: non apparenté 9/10, unité de sang placentaire ou apparenté haploidentique. Ces deux derniers offrent un avantage théorique en terme de délai de recherche du donneur. L'étude a pour but de comparer la survie globale dans les 18 mois à partir de l'indication de greffe, en l'absence de donneur génoidentique, entre 4 groupes de patients allogreffés : donneur non apparenté HLA 10/10, non apparenté HLA 9/10, unité de sang placentaire et donneur apparenté haploidentique.

Cette étude rétrospective de registre, multicentrique, inclut 1302 patients adultes atteints de LAM allogreffés entre 2012 et 2016 avec des cellules souches issues d'un donneur non apparenté 10/10 (n=803), d'un donneur non apparenté 9/10 (n=219), d'unités de sang placentaire $(n=153)$ ou d'un donneur apparenté haploidentique $(n=127)$. La survie globale post-inscription, la survie globale post-greffe et la mortalité liée au traitement ont été évaluées par analyse multivariée en ajustant sur différents facteurs.

La survie globale des patients à 18 mois post-inscription n'est pas significativement différente selon le type de donneurs: $67,5 \%$ [IC 95\%, 64,0\%-70,9\%] pour les 10/10, 62,8\% [IC 95\%, 55,9\%-69,7\%] pour les 9/10, 65,1\% [IC 95\%, 57,3\%-72,9\%] pour les sangs de cordon et $66,6 \%$ [IC 95\%, 58,0\%-5,2\%] pour les haploidentiques $(p=0,70)$. De même, la survie globale à 12 mois post-greffe n'est pas significativement différente : respectivement 67,9\% [IC 95\%, 64,5\%-71,3\%] ; 60,3\% [IC 95\%, 53,3\%-67,4\%] ; 67,0\% [IC 95\%, 59,3$74,7 \%$ ] et $60,3 \%$ [IC 95\%, 51,3\%-69,2\%] $(\mathrm{p}=0,14)$. La mortalité liée au traitement à 12 mois post-greffe n'est pas non plus significativement différente dans les 4 groupes après 
ajustement. Il existe une corrélation entre un délai inscription-greffe court et une meilleure survie ainsi qu'une moindre mortalité liée au traitement dans les 12 mois post-greffe: $\mathrm{HR}=1.04[1.02-1.06](\mathrm{p}<0.0001)$.

Cette étude originale prend en compte, dans le résultat de la greffe, le délai de recherche du donneur et la nature des différents donneurs alternatifs pour des greffes récentes. L'étude a été restreinte aux leucémies aiguës myéloïdes de l'adulte avec un suivi d'au moins 12 mois post-allogreffe. Pour autant, il n'y a pas de différence de survie globale, montrant que les équipes de greffe ont pu s'adapter pour gérer les complications des différents donneurs alternatifs. Ces données, comme d'autres études, soulignent un impact favorable du délai court entre l'inscription et l'allogreffe sur la survie post-greffe.

Mots-clés: Allogreffe de cellules souches hématopoïétiques, leucémie aiguë myéloïde, donneurs alternatifs, survie globale, délai inscription-greffe, 


\section{ABSTRACT}

Allogeneic hematopoietic stem cell transplantation is the only potentially curative therapy for high-risk acute myeloid leukemia. In the absence of an HLA-matched related or unrelated donor (MRD or MUD), the best alternative donor source remains controversial. Umbilical cord blood and haploidentical donors offer a time advantage when considering the duration from treatment indication to transplantation.

This retrospective multicenter study of a French registry compares overall survival for alternative donor transplants in the 18 months following decision to transplant in the absence of a MRD between four groups of transplanted patients: MUD (control); HLAmismatched MUD (mMUD); umbilical cord blood (UCB); and haploidentical (haplo). Between March 2012 and July 2016, 1302 patients were transplanted with MUD (n=803), mMUD $(\mathrm{n}=219)$, UCB $(\mathrm{n}=153)$ and haplo $(\mathrm{n}=127)$ donors. Multivariate analyses were conducted for overall survival 18 months after registration, overall survival after transplant, and transplant-related mortality, with adjustment for the several variables.

After adjustment, the type of donor did not influence any of the three endpoints. Our results confirmed the significant negative impact of a longer time interval between registration and transplant: $\mathrm{HR}=1.04[1.02-1.06](\mathrm{p}<0.0001)$. This indicates a positive correlation between better survival and shorter registration-to-transplantation wait time.

In the absence of a matched related donor, the alternative stem cell source does not impact early survival in high-risk acute myeloid leukemia patients. When selecting an alternative donor, shorter registration-to-transplantation time must be privileged over donor type.

Keywords: Allogeneic hematopoietic stem cell transplantation, acute myeloid leukemia, alternative donors, overall survival, delay from registration to transplantation. 


\section{INTRODUCTION}

Allogeneic Hematopoietic stem Cell Transplantation (allo-HCT) is considered to be the only potentially curative therapy for patients with high-risk acute myeloid leukemia. HLA Matched Related Donors (MRD) are the gold standard for transplantation purposes, but only $30 \%$ patients have such a donor after consideration of factors such as donor consent and health status. ${ }^{1}$ Patient ethnicity strongly influences the probability of finding a suitable HLA 10/10 or 8/8 Matched Unrelated Donor (MUD), ranging from more than $75 \%$ for Caucasians to less than $20 \%$ for certain ethnic minorities. ${ }^{2}$

In recent years, other graft sources have been increasingly adopted as valid allo-HCT donor sources in the absence of an HLA-matched donor: Umbilical Cord Blood (UCB); haploidentical family donor (haplo); or HLA-misMatched Unrelated Donor (mMUD). Schlenk et al. showed that allo-HCT from an MRD or MUD significantly reduced the risk of death for patients with high-risk Acute Myeloid Leukemia (AML), defined as adverse cytogenetics and/or no response to induction therapy. Furthermore, in a prospective multicenter trial between 1998 and 2004 they observed that MRD and MUD-HCT outcomes were similar. ${ }^{5}$ Other studies found that there was no significant difference between MRD and MUD in terms of Overall Survival (OS), relapse risk and Transplant Related Mortality $(\mathrm{TRM}) .{ }^{4,19}$

Lacking HLA-matched donors, MRD or MUD, the best alternative graft source: mMUD, UCB or haplo donors, remains unknown. Outcomes following mMUD have been associated with an approximately $10 \%$ reduction in OS because of an increase in non-relapse mortality. ${ }^{7}$ Results of UCB-HCT in retrospective registry studies were similar to those of MUD-HCT, although hematopoietic recovery was delayed and graft failure was more

frequent. $^{20}$ In a retrospective multicenter study between 2008 and 2012, Ciurea et al. 
showed, comparable 3-year OS after haplo transplantation compared with MUD transplant for AML with both MyeloAblative- and Reduced Intensity- Conditioning (MAC and RIC) regimens. ${ }^{15}$ Moreover, finding donors can take weeks or even months. Unrelated donors are selected through the International Network Registry. Delays in the process of an unrelated donor search due to logistical issues may increase the risk of disease progression or relapse. ${ }^{21}$ Ruggeri et al. showed that shorter intervals from diagnosis to transplantation were associated with lower incidence of relapse in AML patients $(\mathrm{HR}=0.99, \mathrm{p}=0.02){ }^{22}$ Trends towards increased use of haploidentical donors and a concomitant decrease in cord blood transplantation have been recently confirmed in Europe. ${ }^{23}$

In the present study, we addressed the question of the influence of donor type on early post-transplant outcome taking into account the lapse of time needed to find a donor and the organization the transplantation procedure. We focused on overall survival 18 months after registration in the International Network Registry, over a set period of time and in a relatively homogenous population of adult AML patients. Patients who received mMUD, haplo and UCB stem cells were compared with those who received MUD. 


\section{PATIENTS AND METHODS}

\section{Study design and definitions}

In this retrospective multicenter study, we crossed data from the European Society for Blood and Marrow Transplantation (EBMT) database (ProMISe) with the French bonemarrow donor registry (France Greffe de Moelle) database (SYRENAD). Selection criteria were 1) Adult patients having received a first urgent allo-HCT for AML, 2) transplanted between March 2012 and July 2016 in one of 33 French centers, 3) the source was either a MUD (control group), a mMUD, UCB or a family haplo donor. For MUD, mMUD and UCB sources, date of patient registration was retrieved from the Syrenad database. For patients with a haploidentical donor, the date of registration was considered to be that of the decision to seek an alternative source, i.e. the date of first consultation of the World Marrow Donor Association database or another donor registry. Patients with a sibling donor or who eventually did not receive allo-HCT were excluded. The study was performed in accordance with the Declaration of Helsinki and approved by the scientific committee of the SFGM-TC (French Society for Bone-Marrow Cell Therapy).

Conditioning regimens were considered as myeloablative (MAC) when they included total body irradiation with a dose $>6$ Gray or a total dose of Busulfan $>8 \mathrm{mg} / \mathrm{kg}$ orally or $>$ $6.4 \mathrm{mg} / \mathrm{kg}$ intravenously. All other regimens were defined as reduced-intensity conditioning (RIC). For MUD, mMUD or haplo, peripheral blood or bone marrow could be used. For UCB, we included all transplants regardless of number of transplanted units (single or double) or the degree of HLA-matching. A haplo graft was defined as having a HLA match $\geq 4 / 8$. In this group, only patients receiving an unmanipulated graft with post-transplant cyclophosphamide for graft versus host disease (GVHD) prophylaxis were included. 


\section{End points}

Three end-points were analyzed: Overall Survival After Registration (OSAR), Overall Survival After Transplant (OSAT) and TRM. For OSAR and OSAT, time to death from any cause was measured from the date of patient registration and from the date of alloHCT, respectively. Surviving patients were censored at the date of last contact. For TRM, the event was death of any cause without any relapse. Time to event was measured from the date of allo-HCT and patients were censored at the date of relapse or the date of last contact if no relapse occurred. Last follow-up time was at 18 months for OSAR and at 12 months for OSAT and TRM.

\section{Statistical analysis}

Patient, disease and transplant characteristics in the four treatment groups were compared using the chi-squared test for categorical variables and the Brown-Mood test of medians for continuous variables. Probabilities of overall survival (OSAT and OSAR) were calculated using the Kaplan Meier product-limit estimate and compared between treatment groups by the Log-rank test. Cumulative incidence of TRM was estimated for each group and compared by the Gray test to account for competing risks. ${ }^{24,25}$ Non-adjusted survival and cumulative incidence curves were constructed.

Multivariate analysis was performed to estimate treatment group effect on end-points adjusting on other relevant factors among patient disease and transplant characteristics. All potential factors shown in Table 1, except for stem cell sources incompatible with the UCB treatment group, were directly included in the multivariate analysis and the best model was obtained by stepwise selection of significant factors. The delay between registration and transplant was included in the model only for OSAT and TRM. This factor was not included in the model for survival after registration since the time to transplant was not known $a$ 
priori. A Cox proportional hazard model for OSAR and OSAT, and Fine and Gray model for TRM, were implemented in the SAS Macro \%PSHREG. ${ }^{26,27,28}$ Proportionality was checked and non-proportionality was handled by including interactions with time in the model. $^{29}$ All tests were two-sided and $\mathrm{p}$ values $<0.05$ were considered statistically significant. All analyses were performed using SAS Enterprise Guide for Windows 7.15. 


\section{RESULTS}

\section{Patient characteristics}

A total of 1,302 patients who underwent allo-HCT for AML were included in the study. Of these, $803(61.7 \%)$ patients had a MUD, $219(16.8 \%)$ a mMUD, $153(11.7 \%)$ a UCB transplant and $127(9.8 \%)$ received a haplo transplant. Table 1 shows patient and transplantation characteristics.

Gender was not significantly different between transplant groups. The median age at registration was 53.7 years. The stem cells were most frequently from peripheral blood. Disease status at transplantation was Complete Remission (CR) following first line treatment for 833 patients, CR following second line for 209 patients, and CR after $>2$ treatment lines or absence of CR for 260 patients. Some patients (7-12\%) had secondary AML. The proportion of patients having RIC wasn't different between the 4 groups. The median delay between registration and transplant was 3.5 months. There were no differences in the recipients' cytogenetic/molecular risk (high, intermediate, poor) between groups. The proportion of haplo transplants increased over the study period.

\section{Interval from registration to transplant differs between donor types}

Times from registration to transplant for each group are shown in Table 1. The median registration-to-transplant intervals (with ranges) were significantly different between groups: MUD 104 days (30-1149); mMUD 122 days (54-1150); UCB 91 days (22-713); haplo 135 days $(27-1170)(\mathrm{p}<0.0001)$.

\section{Donor type did not influence early overall survival from registration}


Before adjustment for other variables, OSAR did not appear to change with donor type (Figure 1). The 18-month OSAR was as follows: MUD 67.5\% (IC 95\% [64.0\% 70.9\%]); mMUD 62.8\% (IC 95\% [55.9\% - 69.7\%]); UCB 65.1\% (IC 95\% [57.3\% - 72.9\%]); haplo $66.6 \%$ (IC 95\% [58.0\% - 75.2\%]).

Multivariate analysis results for OSAR are shown in Table 2. Factors not shown in the tables were not significant. Factors having a negative impact on OSAR were: absence of remission after 2 lines of treatment: $H R=1.893[1.529-2.344](\mathrm{p}<00001)$; high-risk cytogenetic/molecular prognosis (with a time dependent effect): $\mathrm{HR}=1.054$ at 1 month, 1.112 at 3 months, 1.216 at 12 months $(\mathrm{p}=0.0001)$; and age: $\mathrm{HR}=1.008$ [ $1-1.015]$ $(p=0.0403)$ for each additional year. Only donor $^{+} /$patient $^{-}$cytomegalovirus status had a significant positive impact: $\mathrm{HR}=0.709[0.509-0.988](\mathrm{p}=0.042)$ on OSAR. Adjusting on these variables, donor type was not found to influence OSAR.

\section{Donor type did not influence early overall survival from transplantation}

Before adjustment on other factors, OSAT did not differ among donor types (Figure 2). The 12-month OSAT was as follows: MUD 67.9\% (IC 95\% [64.5\% - 71.3\%]); mMUD 60.3\% (IC 95\% [53.3\% - 67.4\%]); UCB 67.0\% (IC 95\% [59.3\% - 74.7\%]); haplo 60.3\% (IC $95 \%[51.3 \%-69.2 \%])$.

Multivariate analysis results for OSAT are shown in Table 3. Factors having a negative impact on OSAT were: absence of remission after 2 lines of treatment: $\mathrm{HR}=2.15$ $[1.743-2.651](\mathrm{p}<0.0001)$; the delay between registration and transplant, with a time dependent effect: $H R=1.006$ at 1 month after the transplant, 1,011 at 3 months, 1,021 at 12 months $(p=0.0008)$; and age $H R=1.012[1.005-1.02](p=0.0008)$ for each additional year. Intermediate-risk cytogenetic/molecular prognosis had a significant positive impact: 
$\mathrm{HR}=0.718[0.59-0.874](\mathrm{p}=0.001)$. Adjusting for these variables, donor type was not found to influence OSAT.

\section{Donor type did not influence transplant related mortality}

Multivariate analysis results for TRM are shown in Table 4. Factors not shown in the tables were found to be not significant. The delay between registration and transplant had a significantly negative impact on TRM: HR=1.04 [1.02 - 1.06] $(\mathrm{p}<0.0001)$, as did the combination of female donor to male recipient versus others: $\mathrm{HR}=1.43[1.05-1.95]$ $(\mathrm{p}<0.024)$, age: $\mathrm{HR}=1.01[1.00-1.02] \quad(\mathrm{p}=0.039)$, and absence of complete remission after 2 lines of treatment with a negative time dependent effect: $H R=4.75$ at transplant, 3.78 at 1 month, 3.00 at 3 months and 2.04 at 12 months $(\mathrm{p}=0.0012)$. There was a significant positive impact of a CMV donor ${ }^{+} /$patient $^{-}$status: $\mathrm{HR}=0.62[0.39-0.99](\mathrm{p}=0.0458)$ versus others. After adjustment for these variables, the donor type was not linked to TRM.

TRM at 12 months appeared significantly different between the 4 groups before adjusting for other variables (Figure 3): MUD 16.9\% (IC 95\% [14.4\% - 19.8\%]); mMUD 22.8\% (IC 95\% [17.9\% - 28.9\%]), UCB 19.6\% (IC 95\% [13.7\% - 26.4\%]); haplo 25.4\% (IC $95 \%[18.1 \%-33.4 \%])(\mathrm{p}=0.0426)$. 


\section{DISCUSSION}

For patients with high-risk AML in need of an allo-HCT but who lack an HLAmatched donor the best choice of alternative stem cell source remains controversial. The different types of alternative donors have advantages and drawbacks in terms of rapidity of obtaining stem cells, efficacy and tolerability, and the criteria for selecting one type of alternative donor over another are not well established. In a competing risk setting, we compared the early survival of four groups of patients who received transplants from either MUD (control group) or different types of alternative donors. Adjustment on other variables allowed for time-dependent effects on allo-HCT outcomes extending the standard Coxregression models so as to obtain more accurate risk estimates. For OSAR, significant variables were: advanced disease status, age, high-risk cytogenetics and cytomegalovirus status. For OSAT, significant variables were: advanced disease status, age, intermediate-risk cytogenetics (positive effect), and delay from registration to transplant. For TRM, significant variables were: disease status, age, female donor to male recipient, cytomegalovirus status and delay from registration to transplant.

Our main observation was the absence of any influence of donor type on early overall survival following allo-HCT, suggesting that all donor types should still be promoted.

Moreover, we confirmed the positive impact of a shorter time interval between diagnosis and transplant on overall survival and TRM. ${ }^{22}$ The time needed to find a suitable donor remains a crucial issue particularly when an urgent allo-HCT is indicated. Reasons for the choice of alternative donor were not registered in the database. Usually the decision to use an alternative donor source follows an unsuccessful search for a related donor and after registration in the registry. Then, a MUD is sought and lastly the use of a 
UCB or haplo donor is envisaged. This explains the significantly longer wait for patients in the haploidentical group: 4.4 months $(\mathrm{p}<0.0001)$; whereas for MUD or UCB the median delay between registration and transplantation was around 3.4 and 3 months respectively. There was some heterogeneity between our centers as 2 centers sought haploidentical donors before inscription on the registry. In the literature, similar results are reported. According to to Schlenk et al., the median time from diagnosis to allo-HCT was 4.9 months in a prospective evaluation of allo-HCT from MRD or MUD. ${ }^{5}$ The median delay was 4.7 months in a study by Versluis et al. but longer ( 5.8 months) for alternative donors. ${ }^{7}$ One of the advantages of haplo HCT is the rapid availability of donors both for transplant procedure and for subsequent adaptive immunotherapies. It is possible that if haplo HCT had been sought as soon as the unavailability of MRD or MUD were acknowledged then the delay to transplant would be shorter and the outcomes better. This needs to be tested in a randomized clinical trial. Moreover, costs of registration would be avoided.

Our results for TRM (before adjustment) following mMUD are in line with a recent meta-analysis of 7 retrospective studies comparing MUD and mMUD HCT which showed a $27 \%$ increased risk of mortality for recipients of a mMUD. ${ }^{30}$ It is recognized that graft versus host disease and subsequent TRM is more frequent in mMUD recipients. ${ }^{4}$ Insufficient statistical power might explain the results after adjustment.

With the recent diversification in transplant techniques: the introduction of RIC and non-myeloablative regimens; changes in immunosuppressive strategies; improvement in supportive care; and classification according to cytogenetic score, a decrease in TRM after allo-HCT from alternative donors and particularly haploidentical donors has been observed. These changes in transplantation procedures and care impose caution on the interpretation of the results and data from older retrospective studies. 
Our study has some limitations; particularly its retrospective registry-based design and the heterogeneity of transplant procedures across French centers. We were unable to override physician and/or center intentions and preferences when choosing an alternative donor. During the period from 2012 to 2016, haploidentical transplant was still considered as a second intention treatment by most of the centers. This explains the longer interval between registration and transplant in this group. We might have observed a better OS for the haplo group if haploidentical transplant had been used systematically in first intention. Nevertheless, all haplo HCT were conducted with unmanipulated grafts and cyclophosphamide was used for immunosuppression post-transplant, giving a relatively homogeneous haplo procedure. To limit heterogeneity we restricted our study to high-risk AML patients with an urgent indication for transplant and a short follow-up, evaluating only early transplant complications. A longer follow-up would be required to study relapse and long-term survival. Also, to limit heterogeneity due to shifts in practices we restricted the study a short period of time (2012-2016).

Some potentially useful data had not been included in the database, such as minimal residual disease pre-transplant data, a prognostic factor which influences transplant outcomes.

To our knowledge this study is the first of its kind, taking into account registration to transplant delay and three different alternative donor types. 


\section{CONCLUSION}

For AML patients requiring allo-HCT but lacking an HLA-MRD or HLA-MUD alternative stem cell sources hold promise. In this large cohort, donor type did not influence early overall survival. The delay between registration and transplant significantly impacted OS and TRM. Thus, in clinical practice reducing the delay between registration and transplant is more important than the choice of donor type. The challenge is to minimize the time spent finding a donor. Using alternative donors in first intention would permit less time searching for a donor and may improve transplant outcomes. This is supported by the increasing use of haplo donors, with encouraging results. ${ }^{23}$ 


\section{CONCLUSION}

THÈSE SOUTENUE PAR : Clémence DETEIX-SANTANA

\section{ANALYSE DE LA SURVIE DES PATIENTS ALLOGREFFÉS POUR HEMOPATHIE MALIGNE EN L'ABSENCE DE DONNEUR GENOIDENTIQUE}

\section{CONCLUSION :}

Jusque là encore, pour les patients n'ayant pas de donneur génoidentique ou non familial HLA 10/10, le choix entre un donneur HLA 9/10, un sang de cordon ou un donneur familial haploidentique dépend largement de chaque centre de greffe. Aucun essai ni rétrospectif ni prospectif ne montre la supériorité d'un de ces 3 types de donneurs.

Notre étude montre qu'il n'y a pas d'influence du type de donneur sur la survie précoce post allogreffe dans une cohorte homogène de patients atteints de LAM en l'absence de donneur HLA compatible. De même, après ajustement aux différentes variables, il n'y a pas de différence significative de TRM entre les 4 groupes, dans l'année qui suit la transplantation. Ces résultats soulignent que les équipes de greffe ont pu s'adapter pour gérer les complications précoces quel que soit le type de donneur.

Par ailleurs, notre étude révèle un impact favorable d'un délai court entre l'inscription et l'allogreffe sur la survie précoce. En pratique clinique, il est d'intérêt de raccourcir le délai d'organisation de greffe pour améliorer la survie post-transplantation. Finalement, l'utilisation de donneurs alternatifs en première intention pourrait permettre de raccourcir le temps de recherche du donneur et ainsi d'améliorer la survie post-allogreffe. Ces données sont en accord avec des résultats encourageants suite à l'utilisation croissante de donneurs haploidentiques.

Le message de cette étude, en termes de santé publique, souligne l'intérêt de l'accès à tous les types de donneurs pour diversifier le choix des équipes de greffe et offrir un donneur potentiel pour chaque indication le plus rapidement possible.

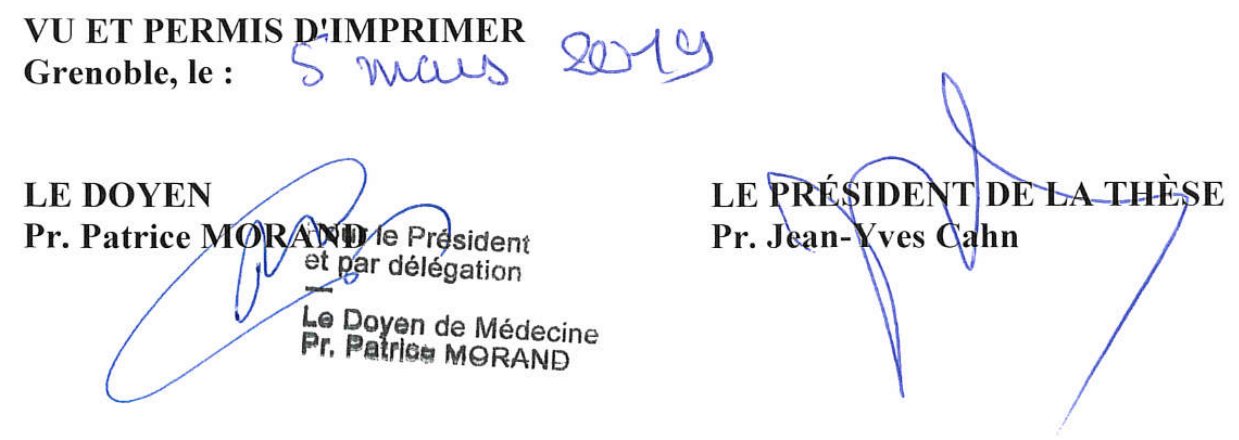




\section{BIBLIOGRAPHIE}

1. Tiercy, J.-M. How to select the best available related or unrelated donor of hematopoietic stem cells? Haematologica 101, 680-687 (2016).

2. Gragert, L. et al. HLA match likelihoods for hematopoietic stem-cell grafts in the U.S. registry. N. Engl. J. Med. 371, 339-348 (2014).

3. Gupta, V. et al. Comparable survival after HLA-well-matched unrelated or matched sibling donor transplantation for acute myeloid leukemia in first remission with unfavorable cytogenetics at diagnosis. Blood 116, 1839-1848 (2010).

4. Saber, W. et al. Outcomes after matched unrelated donor versus identical sibling hematopoietic cell transplantation in adults with acute myelogenous leukemia. Blood 119, 39083916 (2012).

5. Schlenk, R. F. et al. Prospective evaluation of allogeneic hematopoietic stem-cell transplantation from matched related and matched unrelated donors in younger adults with high-risk acute myeloid leukemia: German-Austrian trial AMLHD98A. J. Clin. Oncol. Off. J. Am. Soc. Clin. Oncol. 28, 4642-4648 (2010).

6. Hows, J. M. et al. Comparison of long-term outcomes after allogeneic hematopoietic stem cell transplantation from matched sibling and unrelated donors. Bone Marrow Transplant. 38, 799 805 (2006).

7. Versluis, J. et al. Alternative donors for allogeneic hematopoietic stem cell transplantation in poor-risk AML in CR1. Blood Adv. 1, 477-485 (2017).

8. Lee, S. J. et al. High-resolution donor-recipient HLA matching contributes to the success of unrelated donor marrow transplantation. Blood 110, 4576-4583 (2007).

9. Bejanyan, N., Haddad, H. \& Brunstein, C. Alternative Donor Transplantation for Acute Myeloid Leukemia. J. Clin. Med. 4, 1240-1268 (2015).

10. Peffault de Latour, R. et al. Similar overall survival using sibling, unrelated donor, and cord blood grafts after reduced-intensity conditioning for older patients with acute myelogenous leukemia. Biol. Blood Marrow Transplant. J. Am. Soc. Blood Marrow Transplant. 19, 1355-1360 (2013).

11. Eapen, M. et al. Effect of graft source on unrelated donor haemopoietic stem-cell transplantation in adults with acute leukaemia: a retrospective analysis. Lancet Oncol. 11, 653-660 (2010).

12. Devillier, R. et al. Poor outcome with nonmyeloablative conditioning regimen before cord blood transplantation for patients with high-risk acute myeloid leukemia compared with matched related or unrelated donor transplantation. Biol. Blood Marrow Transplant. J. Am. Soc. Blood Marrow Transplant. 20, 1560-1565 (2014).

13. Passweg, J. R. et al. Use of haploidentical stem cell transplantation continues to increase: the 2015 European Society for Blood and Marrow Transplant activity survey report. Bone Marrow Transplant. 52, 811-817 (2017).

14. Wang, Y. et al. Haploidentical vs identical-sibling transplant for AML in remission: a multicenter, prospective study. Blood 125, 3956-3962 (2015).

15. Ciurea, S. O. et al. Haploidentical transplant with posttransplant cyclophosphamide vs matched unrelated donor transplant for acute myeloid leukemia. Blood 126, 1033-1040 (2015). 
16. Davies, S. M., Ramsay, N. K. \& Weisdorf, D. J. Feasibility and timing of unrelated donor identification for patients with ALL. Bone Marrow Transplant. 17, 737-740 (1996).

17. Lee, C. J. et al. Haploidentical hematopoietic cell transplantation for adult acute myeloid leukemia: A position statement from the Acute Leukemia Working Party of the European Society for Blood and Marrow Transplantation. Haematologica (2017). doi:10.3324/haematol.2017.176107

18. Agence de la biomédecine - Le rapport annuel médical et scientifique 2017. Available at: https://www.agence-biomedecine.fr/annexes/bilan2017/donnees/cellules/04-national/synthese.htm. (Accessed: 19th March 2019)

19. Yakoub-Agha, I. et al. Allogeneic marrow stem-cell transplantation from human leukocyte antigen-identical siblings versus human leukocyte antigen-allelic-matched unrelated donors (10/10) in patients with standard-risk hematologic malignancy: a prospective study from the French Society of Bone Marrow Transplantation and Cell Therapy. J. Clin. Oncol. Off. J. Am. Soc. Clin. Oncol. 24, 5695-5702 (2006).

20. Raiola, A. M. et al. Unmanipulated haploidentical transplants compared with other alternative donors and matched sibling grafts. Biol. Blood Marrow Transplant. J. Am. Soc. Blood Marrow Transplant. 20, 1573-1579 (2014).

21. Davies, S. M., Ramsay, N. K. \& Weisdorf, D. J. Feasibility and timing of unrelated donor identification for patients with ALL. Bone Marrow Transplant. 17, 737-740 (1996).

22. Ruggeri, A. et al. Comparison of outcomes after unrelated cord blood and unmanipulated haploidentical stem cell transplantation in adults with acute leukemia. Leukemia 29, 1891-1900 (2015).

23. Passweg, J. R. et al. Hematopoietic SCT in Europe 2013: recent trends in the use of alternative donors showing more haploidentical donors but fewer cord blood transplants. Bone Marrow Transplant. 50, 476-482 (2015).

24. Kaplan EL \& Meier P. Nonparametric estimation for incomplete observations. J. Am. Stat. Assoc. 457-481 (1958).

25. Gray Robert J. A Class of K-Sample Tests for Comparing the Cumulative Incidence of a Competing Risk. The Annals of Statistics 1141-1154 (1988).

26. Kohl, M., Plischke, M., Leffondré, K. \& Heinze, G. PSHREG: a SAS macro for proportional and nonproportional subdistribution hazards regression. Comput. Methods Programs Biomed. 118, 218-233 (2015).

27. Fine, J. P. \& Gray, R. J. A Proportional Hazards Model for the Subdistribution of a Competing Risk. J. Am. Stat. Assoc. 94, 496-509 (1999).

28. Cox, D. R. Regression Models and Life-Tables. J. R. Stat. Soc. Ser. B Methodol. 34, 187-220 (1972).

29. Grambsch, P. M. \& Therneau, T. M. Proportional hazards tests and diagnostics based on weighted residuals. Biometrika 81, 515-526 (1994).

30. Kekre, N. et al. Impact of HLA-Mismatch in Unrelated Donor Hematopoietic Stem Cell Transplantation: A Meta-Analysis. Am. J. Hematol. 91, 551-555 (2016). 


\section{TABLES AND FIGURES}

Table 1. Patient and transplantation characteristics

\begin{tabular}{|c|c|c|c|c|c|}
\hline \multirow[b]{2}{*}{$\begin{array}{c}\text { patient and transplant } \\
\text { characteristics }\end{array}$} & \multicolumn{4}{|c|}{ Donor type } & \multirow[b]{2}{*}{$\mathbf{p}$} \\
\hline & $\begin{array}{c}\text { MUD 10/10 } \\
\mathrm{N}=803(61 \%)\end{array}$ & $\begin{array}{r}\text { mMUD 9/10 } \\
\mathrm{N}=219(17 \%)\end{array}$ & $\begin{array}{c}\text { UCB } \\
\mathrm{N}=153(11 \%)\end{array}$ & $\begin{array}{c}\text { haplo } \\
\mathrm{N}=127(10 \%)\end{array}$ & \\
\hline $\begin{array}{l}\text { Age at registration } \\
\text { median } \\
\text { range }\end{array}$ & $\begin{array}{c}55 \\
15-72\end{array}$ & $\begin{array}{c}52 \\
15-71\end{array}$ & $\begin{array}{c}49 \\
15-73\end{array}$ & $\begin{array}{c}55 \\
20-73\end{array}$ & 0.0002 \\
\hline $\begin{array}{l}\text { Gender } \\
\text { male } \\
\text { female }\end{array}$ & $\begin{array}{l}426(53 \%) \\
377(47 \%)\end{array}$ & $\begin{array}{l}117(53 \%) \\
102(47 \%)\end{array}$ & $\begin{array}{l}78(51 \%) \\
75(49 \%)\end{array}$ & $\begin{array}{l}71(56 \%) \\
56(44 \%)\end{array}$ & NS \\
\hline $\begin{array}{l}\text { Cytogenetic/molecular risk g } \\
\text { high } \\
\text { intermediate } \\
\text { poor }\end{array}$ & $\begin{array}{l}\text { up } \\
234(29 \%) \\
409(51 \%) \\
160(20 \%)\end{array}$ & $\begin{array}{c}76(35 \%) \\
107(49 \%) \\
36(16 \%)\end{array}$ & $\begin{array}{l}49(32 \%) \\
70(46 \%) \\
34(22 \%)\end{array}$ & $\begin{array}{l}42(33 \%) \\
69(54 \%) \\
16(13 \%)\end{array}$ & $\mathrm{NS}$ \\
\hline $\begin{array}{l}\text { Secondary AML } \\
\text { Yes } \\
\text { No } \\
\end{array}$ & $\begin{array}{c}68(8 \%) \\
735(92 \%)\end{array}$ & $\begin{array}{c}16(7 \%) \\
203(93 \%)\end{array}$ & $\begin{array}{c}14(9 \%) \\
139(91 \%)\end{array}$ & $\begin{array}{c}15(12 \%) \\
112(88 \%)\end{array}$ & NS \\
\hline $\begin{array}{l}\text { Registration year } \\
2012 \\
2013 \\
2014 \\
2015 \\
\end{array}$ & $\begin{array}{l}173(22 \%) \\
264(33 \%) \\
247(30 \%) \\
119(15 \%) \\
\end{array}$ & $\begin{array}{l}59(27 \%) \\
67(30 \%) \\
65(30 \%) \\
28(13 \%) \\
\end{array}$ & $\begin{array}{c}53(35 \%) \\
45(29 \%) \\
44(29 \%) \\
11(7 \%) \\
\end{array}$ & $\begin{array}{l}18(14 \%) \\
37(29 \%) \\
44(35 \%) \\
28(22 \%) \\
\end{array}$ & 0.0008 \\
\hline $\begin{array}{l}\text { Disease status at transplant } \\
\mathrm{CR} 1 \\
\mathrm{CR} 2 \\
\mathrm{CR}>2 \text { ou non } \mathrm{CR}\end{array}$ & $\begin{array}{l}549(68 \%) \\
103(13 \%) \\
151(19 \%)\end{array}$ & $\begin{array}{l}131(60 \%) \\
44(20 \%) \\
44(20 \%)\end{array}$ & $\begin{array}{l}95(62 \%) \\
33(22 \%) \\
25(16 \%)\end{array}$ & $\begin{array}{l}58(46 \%) \\
29(23 \%) \\
40(31 \%\end{array}$ & $<0.0001$ \\
\hline $\begin{array}{l}\text { Conditioning } \\
\text { MAC } \\
\text { RIC }\end{array}$ & $\begin{array}{l}341(42 \%) \\
462(58 \%)\end{array}$ & $\begin{array}{l}94(43 \%) \\
125(57 \%)\end{array}$ & $\begin{array}{l}69(45 \%) \\
84(55 \%)\end{array}$ & $\begin{array}{l}42(33 \%) \\
85(67 \%)\end{array}$ & NS \\
\hline $\begin{array}{l}\text { TBI } \\
\text { Yes } \\
\text { No } \\
\end{array}$ & $\begin{array}{c}66(8 \%) \\
737(92 \%)\end{array}$ & $\begin{array}{c}17(8 \%) \\
202(92 \%)\end{array}$ & $\begin{array}{l}93(61 \%) \\
60(39 \%)\end{array}$ & $\begin{array}{l}43(34 \%) \\
84(66 \%)\end{array}$ & $<0.0001$ \\
\hline $\begin{array}{l}\text { ATG } \\
\text { Yes } \\
\text { No } \\
\end{array}$ & $\begin{array}{l}676(84 \%) \\
127(16 \%)\end{array}$ & $\begin{array}{c}200(91 \%) \\
19(9 \%)\end{array}$ & $\begin{array}{c}52(34 \%) \\
101(66 \%)\end{array}$ & $\begin{array}{l}33(26 \%) \\
94(74 \%)\end{array}$ & $<0.0001$ \\
\hline $\begin{array}{l}\text { Female donor to male recipi } \\
\text { yes } \\
\text { no }\end{array}$ & $\begin{array}{l}108(13 \%) \\
695(87 \%) \\
\end{array}$ & $\begin{array}{c}38(17 \%) \\
181(83 \%) \\
\end{array}$ & $\begin{array}{c}32(21 \%) \\
121(79 \%) \\
\end{array}$ & $\begin{array}{c}21(17 \%) \\
106(83 \%)\end{array}$ & NS \\
\hline $\begin{array}{l}\text { Cytomegalovirus status pati } \\
\text { pos/neg } \\
\text { neg/pos } \\
\text { pos/pos or neg neg }\end{array}$ & $\begin{array}{l}\text { donor } \\
220(27 \%) \\
481(60 \%) \\
102(13 \%) \\
\end{array}$ & $\begin{array}{c}68(31 \%) \\
30(14 \%) \\
121(55 \%) \\
\end{array}$ & $\begin{array}{l}55(36 \%) \\
24(16 \%) \\
74(48 \%) \\
\end{array}$ & $\begin{array}{c}29(23 \%) \\
10(8 \%) \\
88(69 \%) \\
\end{array}$ & 0.0232 \\
\hline $\begin{array}{l}\text { Source of cells } \\
\text { Bone marrow } \\
\text { Peripheral blood } \\
\end{array}$ & $\begin{array}{l}153(19 \%) \\
650(81 \%) \\
\end{array}$ & $\begin{array}{c}27(12 \%) \\
192(88 \%) \\
\end{array}$ & & $\begin{array}{l}41(32 \%) \\
86(68 \%) \\
\end{array}$ & $<0.0001$ \\
\hline $\begin{array}{l}\text { Time to transplant (month) } \\
\text { median } \\
\text { range }\end{array}$ & $\begin{array}{c}3 \\
1-38 \\
\end{array}$ & $\begin{array}{c}4 \\
2-38 \\
\end{array}$ & $\begin{array}{c}3 \\
1-23 \\
\end{array}$ & $\begin{array}{c}4 \\
1-38 \\
\end{array}$ & $<0.0001$ \\
\hline $\begin{array}{l}\text { Transplant year } \\
2012 \\
2013 \\
2014 \\
2015 \\
2016\end{array}$ & $\begin{array}{c}120(15 \%) \\
224(28 \%) \\
255(32 \%) \\
198(24 \%) \\
6(1 \%)\end{array}$ & $\begin{array}{c}27(12 \%) \\
66(30 \%) \\
74(34 \%) \\
45(21 \%) \\
7(3 \%)\end{array}$ & $\begin{array}{c}33(22 \%) \\
50(33 \%) \\
451(33 \%) \\
17(11 \%) \\
2(1 \%)\end{array}$ & $\begin{array}{c}3(2 \%) \\
27(21 \%) \\
41(32 \%) \\
52(41 \%) \\
4(3 \%)\end{array}$ & $<0.0001$ \\
\hline
\end{tabular}

Abbreviations: AML: acute myeloid leukemia; Haplo: haploidentical family donor; mMUD: HLA-mismatched unrelated donor; MUD: HLA-matched unrelated donor; UCB: Umbilical Cord Blood, CR: Complete Remission, MAC: MyeloAblative Conditioning, RIC: Reduced Intensity Conditioning, TBI: Total Body Irradiation, ATG: Anti-Thymocyte Globulin 
Table 2. Multivariate analysis of post-registration overall mortality

\begin{tabular}{|c|c|c|c|c|}
\hline \multirow[b]{3}{*}{ Disease status CR>2 or not CR (vs CR1 or CR2) } & \multicolumn{4}{|c|}{ Post-registration overall mortality } \\
\hline & \multirow{2}{*}{\begin{tabular}{|l|} 
HR1 \\
1.893 \\
\end{tabular}} & \multicolumn{2}{|c|}{$95 \% \mathrm{Cl}^{2}$} & \multirow{2}{*}{$\begin{array}{l}\text { p value } \\
<.0001\end{array}$} \\
\hline & & 1.529 & 2.344 & \\
\hline Cytomegalovirus status donor+/patient- (vs others) & 0.709 & 0.509 & 0.988 & 0.042 \\
\hline Age at registration ${ }^{3}$ & 1.008 & 1 & 1.015 & 0.0403 \\
\hline \multicolumn{4}{|l|}{$\begin{array}{l}\text { Cytogenetic/molecular high risk } \\
\text { (vs intermediate or poor) }\end{array}$} & \multirow{6}{*}{$\begin{array}{l}\text { baseline effect: NS } \\
\text { Time dependant }{ }^{4}: 0.0001\end{array}$} \\
\hline at point 0 & 1 & 1 & 1 & \\
\hline \multirow{4}{*}{$\begin{array}{l}\text { at } 1 \text { month } \\
\text { at } 3 \text { months } \\
\text { at } 9 \text { months } \\
\text { at } 12 \text { months }\end{array}$} & 1.054 & 1.027 & 1.083 & \\
\hline & 1.112 & 1.054 & 1.173 & \\
\hline & 1.16 & 1.076 & 1.251 & \\
\hline & 1.216 & 1.102 & 1.343 & \\
\hline
\end{tabular}

Table 3. Multivariate analysis of post-transplant overall mortality

\begin{tabular}{|c|c|c|c|c|}
\hline \multirow[b]{3}{*}{ Disease status CR>2 or not CR (vs CR1 or CR2) } & \multicolumn{4}{|c|}{ Post-transplant overall mortality } \\
\hline & \multirow{2}{*}{\begin{tabular}{r|}
$\mathrm{HR}^{1}$ \\
2.15
\end{tabular}} & \multicolumn{2}{|c|}{$95 \% \mathrm{Cl}^{2}$} & \multirow{2}{*}{$\begin{array}{l}\text { p value } \\
<.0001\end{array}$} \\
\hline & & 1.743 & 2.651 & \\
\hline $\begin{array}{l}\text { Cytogenetic/molecular risk intermediate } \\
\text { (vs high or poor) }\end{array}$ & 0.718 & 0.59 & 0.874 & 0.001 \\
\hline Age at registration ${ }^{3}$ & 1.012 & 1.005 & 1.02 & 0.0008 \\
\hline $\begin{array}{l}\text { Time between registration and transplant }^{4} \\
\text { at point } 0 \\
\text { at } 1 \text { month } \\
\text { at } 3 \text { months } \\
\text { at } 9 \text { months } \\
\text { at } 12 \text { months }\end{array}$ & $\begin{array}{r}1 \\
1.006 \\
1.011 \\
1.016 \\
1.021\end{array}$ & $\begin{array}{r}1 \\
1.002 \\
1.005 \\
1.007 \\
1.009\end{array}$ & $\begin{array}{r}1 \\
1.009 \\
1.018 \\
1.025 \\
1.034\end{array}$ & $\begin{array}{l}\text { baseline effect: NS } \\
\text { Time dependant }: 0.0008\end{array}$ \\
\hline \multicolumn{5}{|c|}{${ }^{1}$ The Hazard Ratio $(H R)$ is the estimate of the effect of covariate on outcome adjusted on other covariates } \\
\hline \multicolumn{5}{|l|}{${ }^{2} 95 \%$ confidence interval of the HR } \\
\hline \multicolumn{5}{|l|}{${ }^{3}$ linear effect estimate for 1 year difference } \\
\hline${ }^{4}$ linear effect estimate for 1 month difference & & & & \\
\hline${ }^{5}$ log-linear effect & & & & \\
\hline
\end{tabular}

Table 4. Multivariate analysis of TRM

\begin{tabular}{|c|c|c|c|c|}
\hline & \multicolumn{4}{|c|}{ TRM } \\
\hline & \multirow{3}{*}{$\begin{array}{r}\mathrm{HR}^{1} \\
4.745\end{array}$} & \multicolumn{2}{|c|}{$95 \% \mathrm{Cl}^{2}$} & \multirow{4}{*}{$\begin{array}{c}\mathbf{p} \text { value } \\
\\
\text { baseline effect: }<.0001 \\
\text { Time dependant } t^{5}: 0.0012\end{array}$} \\
\hline DISease status CRPL or not CR (VS CRI OT LRZ) & & & & \\
\hline at point 0 & & 2.463 & 9.143 & \\
\hline at 1 month & 3.776 & 2.211 & 6.448 & \\
\hline at 3 months & 3.004 & 1.963 & 4.597 & \\
\hline at 9 months & 2.498 & 1.756 & 3.552 & \\
\hline at 12 months & 2.038 & 1.509 & 2.751 & \\
\hline Female donor to male recipient (vs others) & 1.428 & 1.048 & 1.946 & 0.0239 \\
\hline Cytomegalovirus status donor+/patient- (vs others) & 0.62 & 0.388 & 0.991 & 0.0458 \\
\hline Age at registration $^{3}$ & 1.01 & 1.001 & 1.02 & 0.0389 \\
\hline Time between registration and transplant ${ }^{4}$ & 1.041 & 1.021 & 1.061 & $<.0001$ \\
\hline
\end{tabular}

${ }^{1}$ The Hazard Ratio (HR) is the estimate of the effect of covariate on outcome adjusted on other covariates

${ }^{2} 95 \%$ confidence interval of the HR

${ }^{3}$ linear effect estimate for 1 year difference

${ }^{4}$ linear effect estimate for 1 month difference

${ }^{5}$ log-linear effect 
Figure 1. Overall survival according to donor type after HCT recipient registration for high-risk AML patients

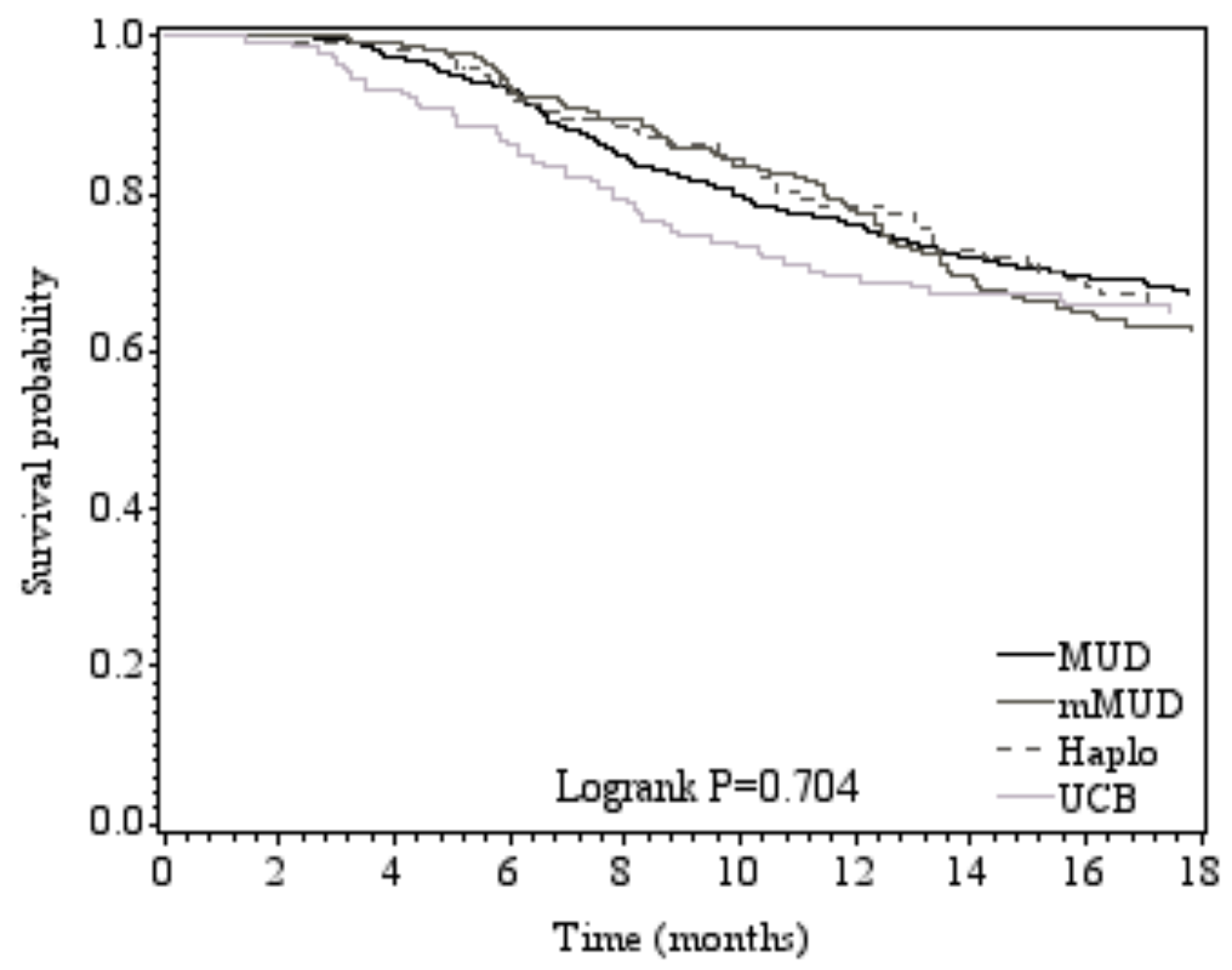

Abbreviations: AML: acute myeloid leukemia; Haplo: haploidentical family donor; mMUD: HLA-mismatched unrelated donor; MUD: HLA-matched unrelated donor; OS: overall survival; UCB: unit cord blood. 
Figure 2. OS according to donor type after transplant for high-risk AML patients

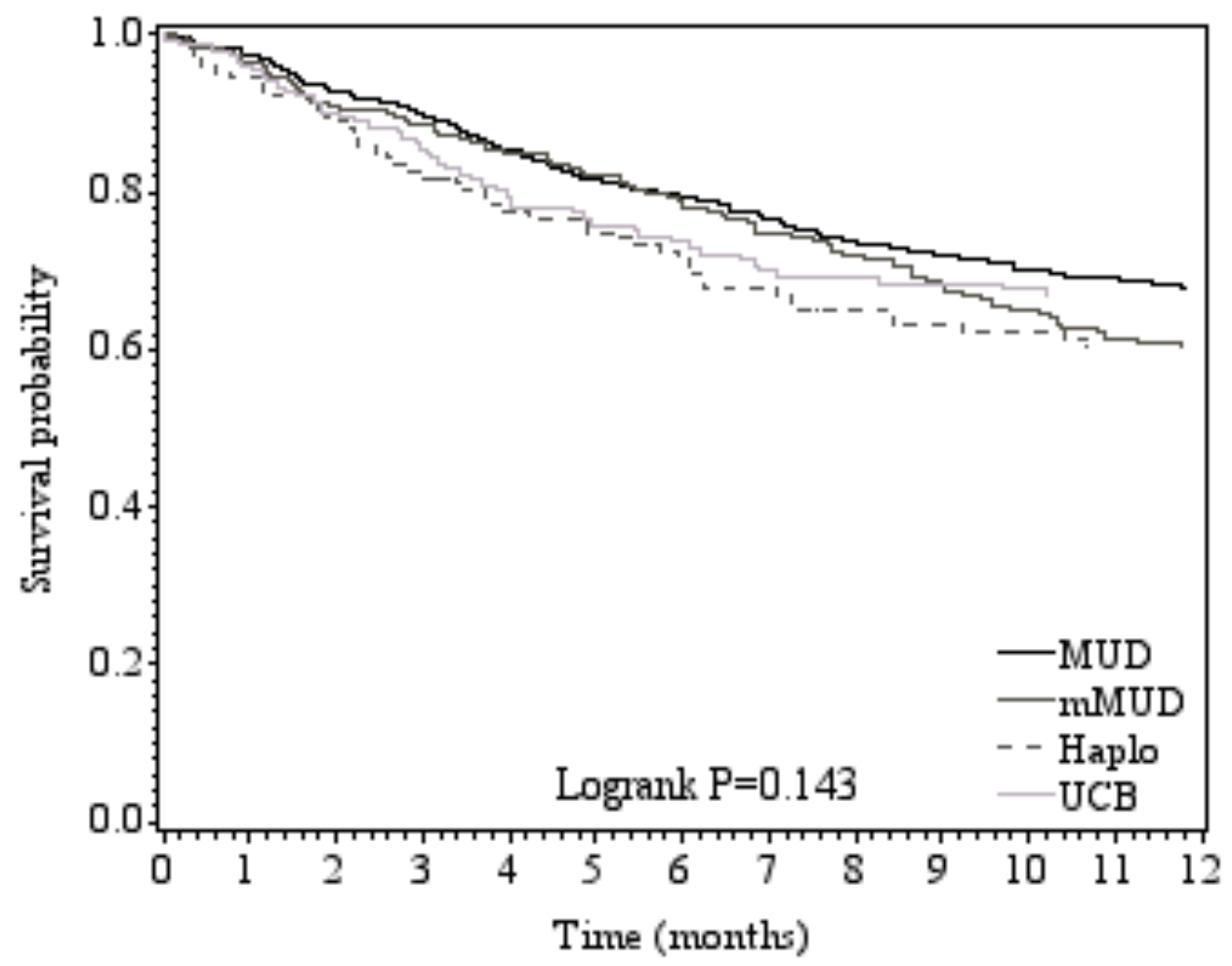

Abbreviations: AML: acute myeloid leukemia; Haplo: haploidentical family donor; mMUD: HLA-mismatched unrelated donor; MUD: HLA-matched unrelated donor; OS: overall survival; UCB: unit cord blood. 
Figure 3. Cumulative TRM probability at time from diagnosis for high-risk AML patients according to donor type

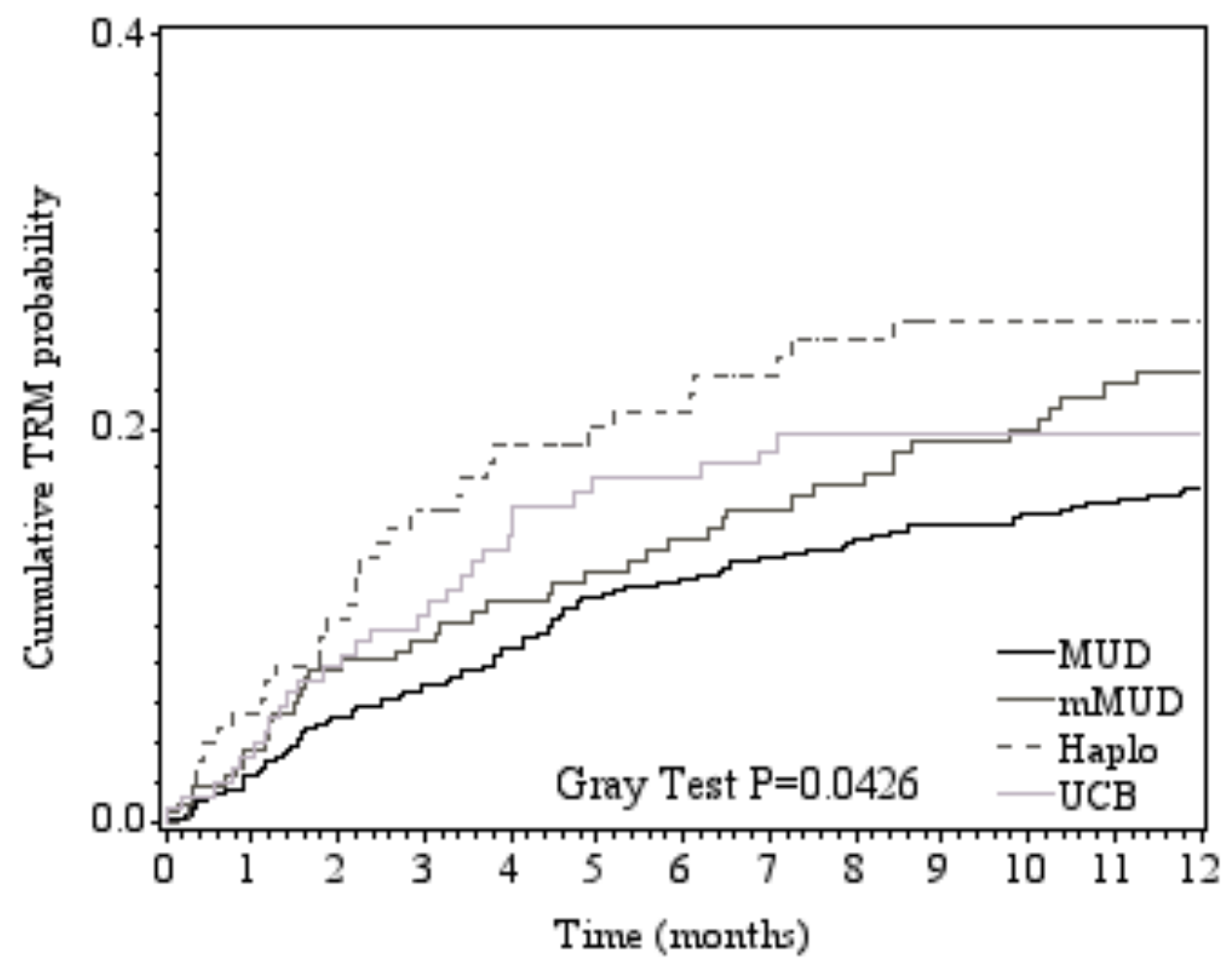

Abbreviations: AML: acute myeloid leukemia; Haplo: haploidentical family donor; mMUD: HLA-mismatched unrelated donor; MUD: HLA-matched unrelated donor; OS: overall survival; UCB: unit cord blood. 


\section{SERMENT D'HIPPOCRATE}

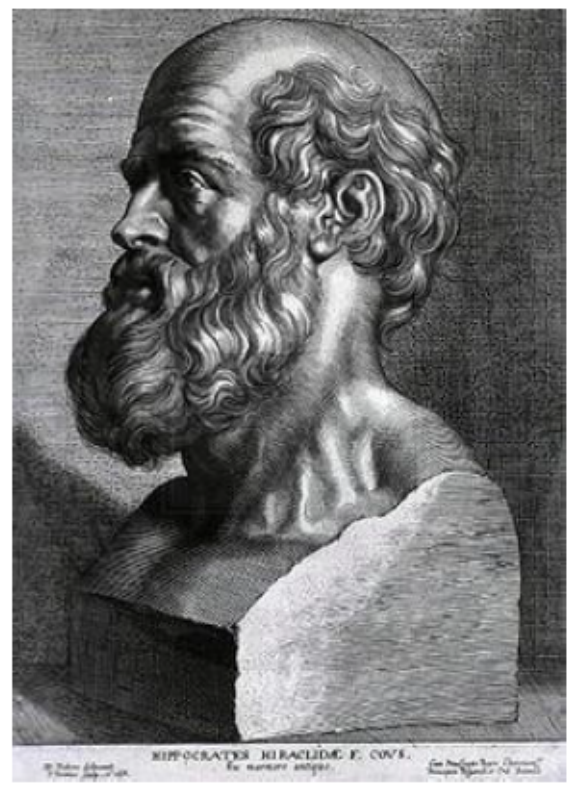

\section{SERMENT D'HIPPOCRATE}

En présence des Maîtres de cette Faculté, de mes chers condisciples et devant l'effigie d'HIPPOCRATE,

Je promets et je jure d'être fidèle aux lois de l'honneur et de la probité dans l'exercice de la Médecine.

Je donnerai mes soins gratuitement à l'indigent et n'exigerai jamais un salaire au dessus de mon travail. Je ne participerai à aucun partage clandestin d'honoraires.

Admis dans l'intimité des maisons, mes yeux n'y verront pas ce qui s'y passe; ma langue taira les secrets qui me seront confiés et mon état ne servira pas à corrompre les mours, ni à favoriser le crime.

Je ne permettrai pas que des considérations de religion, de nation, de race, de parti ou de classe sociale viennent s'interposer entre mon devoir et mon patient.

Je garderai le respect absolu de la vie humaine.

Même sous la menace, je n'admettrai pas de faire usage de mes connaissances médicales contre les lois de l'humanité.

Respectueux et reconnaissant envers mes Mâtres, je rendrai à leurs enfants l'instruction que j'ai reçue de leurs pères.

Que les hommes m'accordent leur estime si je suis fidèle à mes promesses.

Que je sois couvert d'opprobre et méprisé de mes confrères si j'y manque. 


\section{RÉSUMÉ}

\section{Analyse de la survie des patients allogreffés pour hémopathie maligne en l'absence de donneur génoidentique}

L'allogreffe de cellules souches hématopoïétiques est le seul traitement potentiellement curateur des leucémies aiguës myéloïdes (LAM). En l'absence de donneur génoidentique ou compatible en HLA (Human Leukocyte Antigen) 10/10, une allogreffe reste possible grâce à 3 types de donneurs alternatifs: non apparenté 9/10, apparenté haploidentique ou sang de cordon. Ces deux derniers offrent un avantage théorique en terme de délai de recherche du donneur.

Cette étude rétrospective de registre, multicentrique, inclut 1302 adultes atteints de LAM allogreffés entre 2012 et 2016 avec un donneur non apparenté 10/10 ( $\mathrm{n}=803), 9 / 10(\mathrm{n}=219)$, du sang placentaire $(\mathrm{n}=153)$ ou un donneur apparenté haploidentique $(\mathrm{n}=127)$. La survie globale post-inscription, la survie globale postgreffe et la mortalité toxique ont été évaluées par analyse multivariée en ajustant sur différents facteurs.

La survie globale à 18 mois post-inscription et celle à 12 mois post-greffe ne sont pas significativement différentes selon le type de donneur. De même, la mortalité liée au traitement à 12 mois postgreffe n'est pas significativement différente après ajustement. Il existe une corrélation entre un délai inscription-greffe court et une meilleure survie ou une moindre mortalité liée au traitement dans les 12 mois post-greffe : HR=1.04 [1.02-1.06] $(\mathrm{p}<0.0001)$. L'absence de différence de survie globale montre que les équipes de greffe ont pu s'adapter pour gérer les complications des différents donneurs alternatifs.

Ces données, comme d'autres études, soulignent un impact favorable du délai court entre l'inscription et l'allogreffe sur la survie. Ainsi, en pratique clinique, il est d'intérêt de raccourcir le délai d'organisation de la greffe pour améliorer la survie précoce.

Mots-clés: Allogreffe de cellules souches hématopoïétiques, leucémie aiguë myéloïde, donneurs alternatifs, survie globale, délai inscription-greffe.

\section{Influence of alternative donor type on early survival after hematopoietic stem cell transplantation for acute myeloid leukemia lacking a sibling donor}

Allogeneic hematopoietic stem cell transplantation is the only potentially curative therapy for acute myeloid leukemia. In the absence of an HLA-matched related or unrelated donor (MRD or MUD), the best alternative donor source remains controversial. Umbilical cord blood and haploidentical donors offer a shorter delay from indication to transplantation.

This retrospective multicenter study of a French registry compares overall survival in the 18 months following registration in the absence of a MRD between four types of donors. Between 2012 and 2016, 1302 patients were transplanted using MUD (control, $n=803$ ), mismatched MUD ( $\mathrm{n}=219)$, umbilical cord blood $(\mathrm{n}=153)$ and haploidentical $(\mathrm{n}=127)$ donors. Multivariate analyses were conducted for overall survival after registration, after transplant, and transplant-related mortality.

After adjustment for variables, the type of donor did not influence any of the three endpoints. Our results confirmed the significant negative impact of longer time between registration and transplant: $H R=1.04$ $[1.02-1.06](p<0.0001)$. This indicates a positive correlation between better survival and shorter registration-totransplantation wait time.

In the absence of a sibling donor, the alternative stem cell source does not impact early survival in acute myeloid leukemia patients. When selecting an alternative donor, shorter registration-to-transplantation time must be privileged over donor type.

Keywords: Allogeneic hematopoietic stem cell transplantation, acute myeloid leukemia, alternative donors, overall survival, delay from registration to transplantation. 